Article

\title{
Exploiting the Scientific Literature for Performing Life Cycle Assessment about Transportation
}

\author{
Christian Spreafico *(-) and Davide Russo \\ Department of Management Information and Production Engineering, University of Bergamo; \\ 24044 Dalmine (Bg), Italy; davide.russo@unibg.it \\ * Correspondence: christian.spreafico@unibg.it
}

Received: 31 July 2020; Accepted: 11 September 2020; Published: 13 September 2020

check for updates

\begin{abstract}
This paper provides an overview of the environmental impacts of different types of passenger transportation means (i.e., bicycles, motorcycles, cars, buses, trains, and airplanes). The method has been applied to the European scenario. The study was performed by using life cycle assessment in accordance with international standard ISO 14040/44 for assessing the $\mathrm{CO}_{2}$ eq., $\mathrm{SO}_{2}$, and $\mathrm{PM}_{10}$ of the transportation means by exploiting data (i.e., vehicles features and environmental impacts) from 24 scientific papers from the literature that have been manually analyzed. The functional unit is defined as the impact per 1 passenger over $1 \mathrm{~km}$. The study identified that planes are the most impacting for $\mathrm{CO}_{2}$ eq. with up to $380 \mathrm{~g} / \mathrm{pkm}$, while cars are the most impacting for $\mathrm{SO}_{2}$ with up to $1.78 \mathrm{~g} / \mathrm{pkm}$ and $\mathrm{PM}_{10}$ with $0.98 \mathrm{~g} / \mathrm{pkm}$. Electric and hybrid models proved to be significantly better than others, while buses are the most sustainable in general. Referring to the overall European scenario, cars constitute up to $95 \%$ of the overall impacts. By comparing some improvements for reducing the impacts, it emerged that the limitation of diesel cars along with the increase of buses and trains are the most effective. The provided outcomes may be useful for legislators, manufacturers, and users for favoring the choice of the transportation means in a more environmentally conscious way.
\end{abstract}

Keywords: transportation impact; electric transportation; environmental impact; life cycle assessment (LCA)

\section{Introduction}

Globally, transportation means have a considerable environment impact, as they contribute to over $22 \%$ of total greenhouse gas emissions, consume $27 \%$ of final energy demand, consume over half of the available oil [1], and generate up to $60 \%$ of the particulate matter [2]. Furthermore, it is estimated that the reduction of these values due their technological evolution will not be sufficient to compensate for the increases of more than $160 \%$ of requests for passenger and freight transport expected for the period 2020-2050 [3].

For these reasons, legislators and manufacturers are actively working on the problem by introducing a very wide and heterogeneous series of interventions aimed to increase the sustainability of the transportation means through the improvement of engine efficiency, technological and structural updating, the use of alternative energies and fuels, reduction of emissions, route planning, and the introduction of limitations and incentives to purchase. However, the assessment of the sustainability of the transportation means is a vague and sometimes insidious concept, which requires precise definitions and analysis methodologies, which cannot be limited only to the consumption of resources, but should also consider other aspects related to economic issues, social well-being, human health, and ecological integrity so that improvement interventions can be truly focused and useful [4]. Furthermore, the current regulations for the quantification of the environmental impacts applied to the transportation means proved to be incomplete and inaccurate in some of their parts, leading, following 
their application, to incomplete and misleading results, which, considered individually, cannot be used as valid decision-making tools for planning intervention measures [5].

The life cycle assessment (LCA) methodology applied to the transportation means can be used to overcome these limitations, providing rigorous evaluation of the impacts, based on quantitative and accepted measurements, and allowing the comparison of the environmental benefits arising from hypothetical future improvements [6].

Several LCA studies about transportation can be found in many contributions among manufacturing reports, scientific articles, books, conference proceedings, and normative references, which analyze many means of transport in different contexts and with different levels of detail. Some studies follow a bottom-up approach, with which the contributions of the constituting parts are calculated and then composed to obtain the overall value, either by calculating the impacts of a certain transportation means model in a given context of use or comparing two or more models of the same means or different means to fulfil the same function. Among those of the first category, [7] calculated the impact of a heavy metro train in Rome based on technical data from the vehicle manufacturer and the information relating to the actual turnout obtained from the municipal transport company, while [8] presented an analogous study about the impacts of a high-speed train used on the national route of Portugal. In the second category, [9] compared electric and internal combustion engine cars used on the same routes and [10] performed a similar study considering an electric and a fuel cell bicycle, while [11] compared an existing motorcycle with a future model in order to show a comparison over a longer time frame.

Others follow a top-bottom approach by focusing on a given infrastructure or geographical perimeter, taking into account aggregated data on passenger numbers, mass of goods, and use of energy or fuel consumption, and deriving the overall impacts for all the transportation means moving within or through it. Among them, [12] determined the environmental impacts of air transportation in United States starting from the data relating to the total number of passengers and the respective routes, while [13] collected all the environmental impacts deriving from the transport of goods purchased online in London.

Analysing these contributions, the complexity of the topic clearly emerges, due to the presence of many different aspects to be considered for each transportation means (e.g., model, size, structural features, energy consumption, and maintenance) to calculate the impacts and their relations with the parameters of the operative scenarios (e.g., geographical locations, infrastructures, and use modalities). The different models of the same transportation means have an influence on the impacts due to the different design choices, with the selection of types and masses of materials, production sites, and distribution [14]. The adopted technology and type of fuel influence the use efficiency, and they are characterized by a certain availability and sustainability, which also depends on the production and extraction places [10]. The structural features of the vehicle have a direct influence on the impacts over the large part of the life cycle due to the types of used materials and their masses, the required manufacturing processes, the overall weight of the vehicle to be handled during the use phase, and their ability to be handled and processed during end-of-life [15]. The user behavior conditions the choice of the means of transport, the frequency of use, and the mode of use of private vehicles [16]. The geographical location influences the impacts of the transportation means in relation to the possibility of using one of them, the mode of operation, due to the presence of certain primary infrastructure, e.g., roads, secondary infrastructure, e.g., service stations, and the onerousness of their construction, e.g., building tunnels [8]. In addition, the availability of fuels and the electricity mix in a geographical area can also significantly affect the impacts during the use phase of the vehicles [17].

However, despite many contributions in the literature, the emerging results are usually too detailed, often emphasizing only some phases of the product life cycle, such as design, and leaving out important aspects of the others [18]. On the one hand, there is also a tendency to level the results about the impacts on the average values, filtering the specific cases as much as possible in order to better refer to the most diffused habits of the population, while losing important information about the 
different alternative models [19]. Still others use data that does not represent the real-world situation, which they derive from experimental controlled conditions at the laboratories [20].

To overcome these limitations, this paper analyzes all the most common passenger transportation means into a unique study based on LCA methodology, in relation to a certain number of environmental impact indicators, considering referable and well-defined functional units and operational scenarios, where the latter is representative of the overall European Union with the 28 member states (EU-28), also considering the United Kingdom for completeness. In addition, in order to not replicate from scratch the analysis of all the involved transportation means, it was decided to exploit all the reliable sources from scientific literature, to manually extract the useful information, and to relate their outcomes according to the specific objectives of this study.

This study contributes to the analysis of the environmental impacts arising from transportation by providing an extended comparison between the many alternatives and by enlarging the perspective of analysis to the overall European scenario. In this way, the study makes it possible to identify the main criticalities on a macro scale, which is difficult to find in other studies in the literature, and to exhibit the benefits of the common improvements at this level.

The main motivations of this study are: stimulating the users to pay more attention during the choice of the transportation means, both for the use and the purchase, and producers to improve their products toward greater sustainability; increasing the sensitivity of legislators about the environmental problems arising from transportation; and suggesting criteria for the legislators to support decision-making about the strategies to be implemented.

The difference between our article and the previous contributions in the literature should not be sought so much in the single results provided regarding the impacts of the different vehicles, but more in the final result that has been obtained by comparing and combining them. In fact, the impacts of the vehicles have not been recalculated or modified but have only been normalized in order to be able to compare them on the basis of the same functional unit. On the other hand, the main result of this article consists instead in comparing the impacts as such and aggregating and comparing them in relation to the overall European scenario.

Among the other main novelties of this study, it emerged that airplanes, especially short-range ones, are the most impacting transportation means for what concerns the $\mathrm{CO}_{2}$ eq. production, while cars are the most impacting for both $\mathrm{SO}_{2}$ and $\mathrm{PM}_{10}$, although the size represents a fundamental aspect to be taken into account. Buses are the most sustainable vehicles of all (except for bicycles), nevertheless their diffusion is equal to $9 \%$ at European level in terms of travelled distance. Finally, the advantages of electric mobility have been identified over gasoline and diesel vehicles, as well as those of hybrid mobility that in some cases are better than electric (i.e. medium-sized cars and buses).

In addition, the EU-28 aggregation of the data performed in this study made it possible to identify the environmental impact arising from the vehicles and the great impact of diesel cars. In this scenario, the advantages arising from an increased use of public transport have been highlighted, especially in relation to the reduction of $\mathrm{CO}_{2}$ eq., along with those of the reduction of $\mathrm{SO}_{2}$ and $\mathrm{PM}_{10}$ that can be achieved by replacing diesel cars with gasoline ones without necessarily switching to electric mobility, which is more difficult to adopt in short periods.

\section{Methodology}

The starting point of the study was the definition of the initial hypotheses:

Hypothesis 1. Do different means of transport and their models have an influence on impacts? With this hypothesis, we wanted to investigate the role of the main features of different transportation means (e.g., cars vs. buses), i.e., size, power, and infrastructure, and also deepening that by investigating differences between some of the most diffused models of the same transportation means (e.g., electric medium-sized car vs. electric micro car). 
Hypothesis 2. In what way do the population's transportation habits affect the overall impacts? With this hypothesis, we wanted to investigate how collective preferences relating to the use of means of transport can affect the definition of the overall impacts of the transportation means in the territory where the population lives.

Hypothesis 3. Can proper criteria of selection of the transportation means and common technical improvements reduce the overall environmental impacts of transportation? In this case, we wanted to identify the criteria of improvement and to compare them in relation to the benefits they can guarantee on sustainability.

To answer the initial hypotheses through this study, LCA methodology for assessing the environmental impacts was strictly followed in accordance with the international standards ISO 14040 [21] and ISO 14044 [22], which specify principles, requirements, and guidelines for their quantification and communication.

LCA methodology consists of a series of multiple consecutive steps to be followed in strict succession, complying with regulatory requirements to ensure minimum quality criteria so that the results can be sufficiently reliable. The steps of the methodology are grouped in the following four steps:

1. Definition of the goal and scope of the study, or the identification of the technical system to be analyzed, the definition of the functional unit and operative scenario, and the formulation of the motivations of the LCA in order to circumscribe the domain of validity of the study.

2. Collection of the sources of impacts, i.e., the inventory of all the items of the analysis during the product life cycle, e.g., the types of materials and the masses of the components, the auxiliary and consumable materials, and the energy spent in the realization, transport, functioning, and disposal. This phase can be carried out through direct or indirect measurement with an appropriate resource allocation criterion. To reduce the onerousness of this phase, approximations respecting the "cut-off" criteria established by the normative reference can also be introduced. Finally, in this phase, calculation methods and datasets containing the specific impact coefficients of materials and energy are also gathered.

3. Environmental impacts assessment is carried out through the calculation according to the standardized environmental indicators, which quantify the deterioration of ecosystems, direct impacts on human health, and resource depletion by exploiting the data, methods, and tools collected during the second phase of the LCA.

4. Interpretation of the results to be presented in the study consist in their hierarchization based on the magnitude of the environmental impacts, in their discussion, preferably in comparison with the previous literature and considerations about economic and legal aspects, and in the sensitivity analysis to quantify the weight of uncertainties on the overall results.

In this study, all steps of the LCA methodology have been rigorously followed in order to fully respond to the initial assumptions.

During the first step, the objective of the study was reformulated by selecting the transportation means and the phases of their life cycle to consider and by defining the geographical reference scenario. Successively, the models and the main features of each transportation means were collected, and the functional unit was defined by providing a reference unit for normalizing the inventory data [21] and allowing the comparison of the alternatives [22], along with the criteria for data and methods collection and the system boundaries. Finally, the limitations depending on the methodological choices were discussed according to the modalities prescribed by the normative reference.

The data and the methods for the impact calculation were collected during the inventory analysis in order to quantify the environmental impacts associated with the system to be evaluated by means of a mass and energy balance [22] in accordance with the criteria for the selection of the sources.

During the impact assessment, the environmental impacts of the transportation means were calculated by exploiting the collected data and methods.

Through the interpretation of the results, they were expressed by using the selected environmental indicators to permit their comparison and their aggregation in a homogeneous way. Their completeness, 
consistency, and robustness were deeply discussed, and the significant points and recommendations were presented for the intended audience.

In the rest of the paper, each step of the methodology is presented in detail.

\section{Goal and Scope Reformulation}

The goal and scope of the study were reformulated by defining the most diffused passenger transportation means for passengers in EU-28 and the reference scenario.

The transportation means are traditional and electric assisted bicycle (bike), motorcycles (moto), cars (C), buses with different sizes and power modes, trains, and airplanes of different sizes and travel distances, which are commonly and currently marketed and used in all EU member states. The environmental scenario is a mix between the different European characteristics in terms of type of route (i.e., urban, interurban, and mixed), geography, climate, and infrastructure (i.e., electricity mix).

\subsection{Products (Transportation Means) Description}

All the considered transportation means can be classified according to their type, size, and power supply.

Three models of bicycles were considered including a traditional pedal bicycle [23] and two models of electric (E) bicycles with pedal assistance, one of which was battery-operated, of which two models were considered [10,24], and one fuel cell (FC) model [10].

Among the motorcycles, various models of different size and type have been considered. Among them are: an electric moped commonly used in urban centers [25]; two types of motorcycles with a power of $4 \mathrm{~kW}$, one having the internal combustion engine with four-stroke engine $[10,11,26,27]$, and one electric [11,27]; and two types of motorcycles with a power of $50 \mathrm{~kW}$, one with internal combustion engine and one electric, both described in [11].

Three main vehicle families were selected among the cars based on size and power: microcars (MC), medium-sized cars (C), and sport utility vehicles (SUVs). The microcars are three models of two-seater Smart, one gasoline-powered, one electric, and one electric converted (Conv) from a gasoline model, all described in [17]. Among the medium-sized cars, there are several internal combustion models, including one gasoline-powered type VW Golf EURO 5 [9], two diesel equivalents [28,29], one biodiesel [28], one with liquefied petroleum gas (LPG), and one with natural gas (NG), both described by [14]. In addition to these, two models of electric medium-sized cars $[9,14]$ and two hybrids $(\mathrm{H})$ ones [14,30] were considered. The SUVs are four models: gasoline, diesel, and a hybrid, described by [14] and electric [31].

The considered buses are all of the standard size, i.e., with a wheelbase of about 7 meters, not articulated, with two wheel axles and a single plane, one diesel and one hybrid, described by [32], one powered by natural gas [33], and two electric, which are with batteries [34] and with fuel cells, respectively [33].

The considered trains are of three types: two models of lightweight (LW) trains for exclusively urban use, both surface and underground, both described by [12]; two heavyweight (HW) trains [7,35] for underground and suburban or regional urban use; and two models of high-speed (HS) trains with maximum speed above $200 \mathrm{~km} / \mathrm{h}[8,36]$.

The considered airplanes are of three types depending on the route covered: short distance (SD) for 500-1000 km, medium distance (MD) for 1000-4000 km, and long distance (LD) for over $4000 \mathrm{~km}$. In the case of the SD, an Airbus 220 and an Airbus 320, in the MD, an Airbus 320 and a Boeing 737, and in the LD, a Boeing 777 and a Boeing 787 were analyzed [15,18,37].

The map in Figure 1 reports all the considered transportation means. 


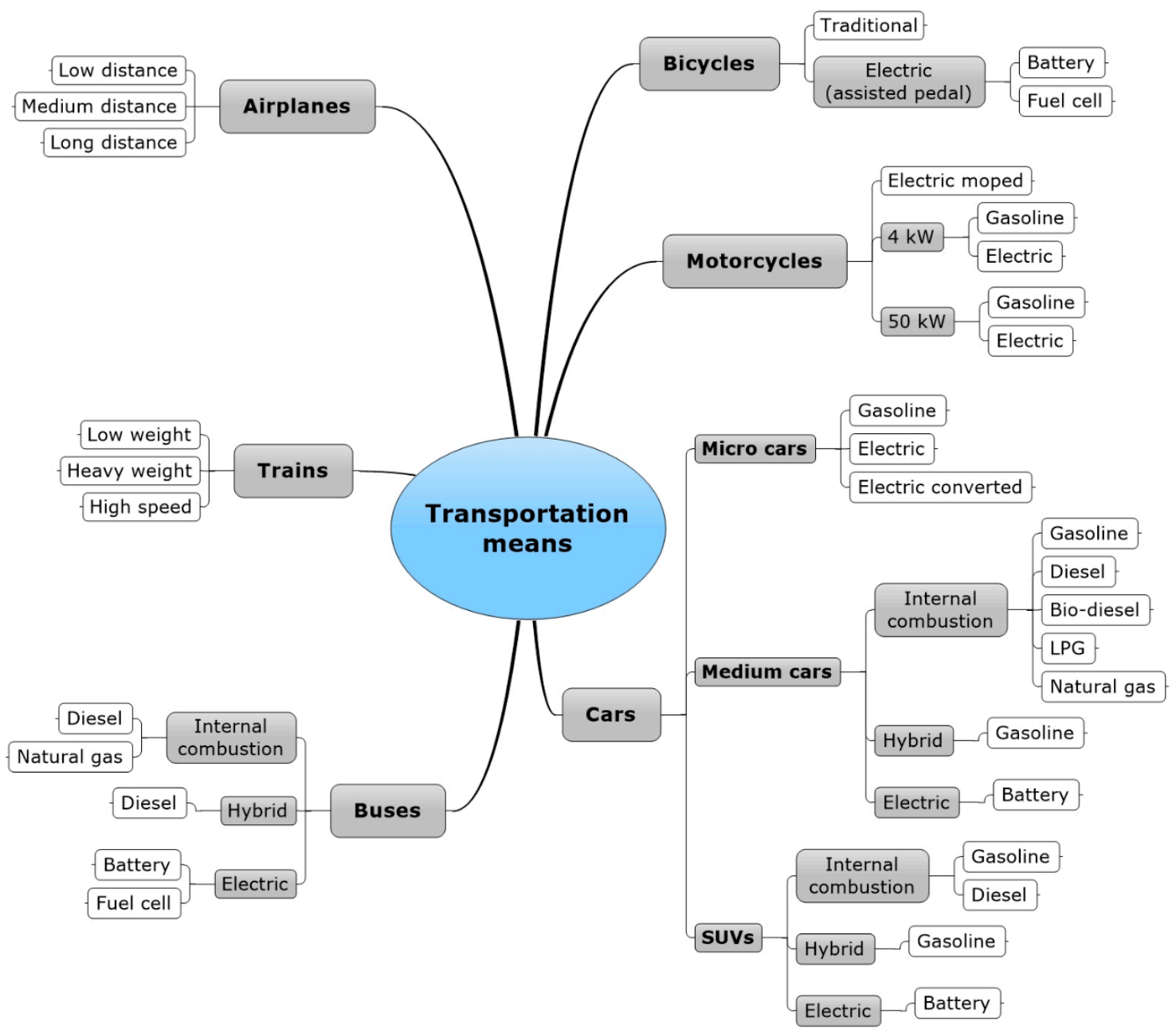

Figure 1. Classification of the considered transportation means.

\subsection{Functional Unit}

The functional unit has been defined as the transport of 1 passenger per $1 \mathrm{~km}$ of distance within the typical European scenario considering the geographic and climatic features of the routes in terms of types of roads and railways (i.e., average slope, percentage of tunnels, and type of terrain).

In addition to the main parameters, other secondary but equally crucial parameters for the comparison of results were also defined in this study, which concern the passenger filling coefficients of the transportation means. In the case of buses, by adopting the average European occupancy coefficient, which consists of 3 passengers per interior $\mathrm{m}^{2}$ [38], and multiplying it by the average bus size considered in this study, an average number of 54 passengers was obtained.

The average train filling coefficient assumes $80 \%$ of seats occupied and 3.2 passengers $/ \mathrm{m}^{2}$ in the standing area [39], whereas for the aircrafts, the number of passengers was fixed according to the maximum single class seating capacity as in [37].

\subsection{Selection of the Sources}

All the considered data and methods have been carefully collected from reliable sources from the scientific literature by selecting only valuable articles from international journals from the Google Scholar database, by using queries containing terms about environmental impact assessment (e.g., "lifecycle assessment", "LCA", "eco assessment", "green assessment", etc.), energy consumption, and the names of the transportation means. All documents contain data about environmental impacts and energy consumptions for which their authors explicitly declared the adherence to reality and the 
use of replicable procedures of updated methods (e.g., Midpoint ReCiPe model), calculation tools (e.g., SimaPro, GaBi), and reliable databases (e.g., Ecoinvent).

To ensure the adherence to the geographical context of application, the selected documents refer to the average European scenario or consider one or more member states. Only some other documents from other countries (e.g., United States) have been considered by collecting only those data also referable to the considered scenario in terms of transportation means diffusion and geographical compatibility of the routes. Almost all the considered documents are from the last ten years, privileging those with less than five, to better adapt to the continuous updating in energy and environmental performances of the transportation means with updated sources.

Finally, we filtered all the sources in a rigorous manner by conserving only those studies that, while meeting all the previous criteria, calculated the environmental impacts following the LCA methodology in a rigorous manner according to the reference standards.

The 24 documents selected from the literature for performing this study are only those reporting data deriving only from experiments on real cases, because we believe that they are more reliable than laboratory experiments, as cited in [20].

Among them, we collected only the results that were obtained according to the same common criteria in terms of allocation and approximation principles, e.g., "data cut-off", so that all the data used in this study can meet the same quality criteria.

This onerous selection process has been necessary, given the heterogeneity of the exploited sources, to ensure the reliability of the results of this study.

\subsection{System Boundaries}

The system boundaries are defined considering the current geographical and infrastructural conditions in Europe.

The material extraction and the manufacturing phases of all the transportation means were included in the study, because the scope of the study is from "cradle to grave", and they can be significantly different between the alternative transportation means and there are fundamentals to compare them. Transportation of raw materials from extraction points to manufacturing sites and transportation related to distribution were excluded from the study to avoid distorting the overall comparison between the alternative transportation means that are produced in different places and due to the variability over time of the location of the production sites.

The use phase was included in the LCA, because its impacts are generally the most consistent for the transportation means within the lifecycle. They include fuel or electricity consumption, the energy spent for maintenance, spare parts, and wear and tear on parts, e.g., the dust of the brakes or leaks of lubricating oil. In addition, during the use phase, the impact of the construction and maintenance of the infrastructure directly used by the transportation means, i.e., road, rail, and airport runway, were also considered. However, impacts arising from other secondary facilities, e.g., airport stations or terminals, and their management were not included.

The end-of-life phase has been included in the LCA, collecting for each domestic component the impacts from literature about the 100:0 approach [40].

Figure 2 graphically summarizes the system boundaries: 


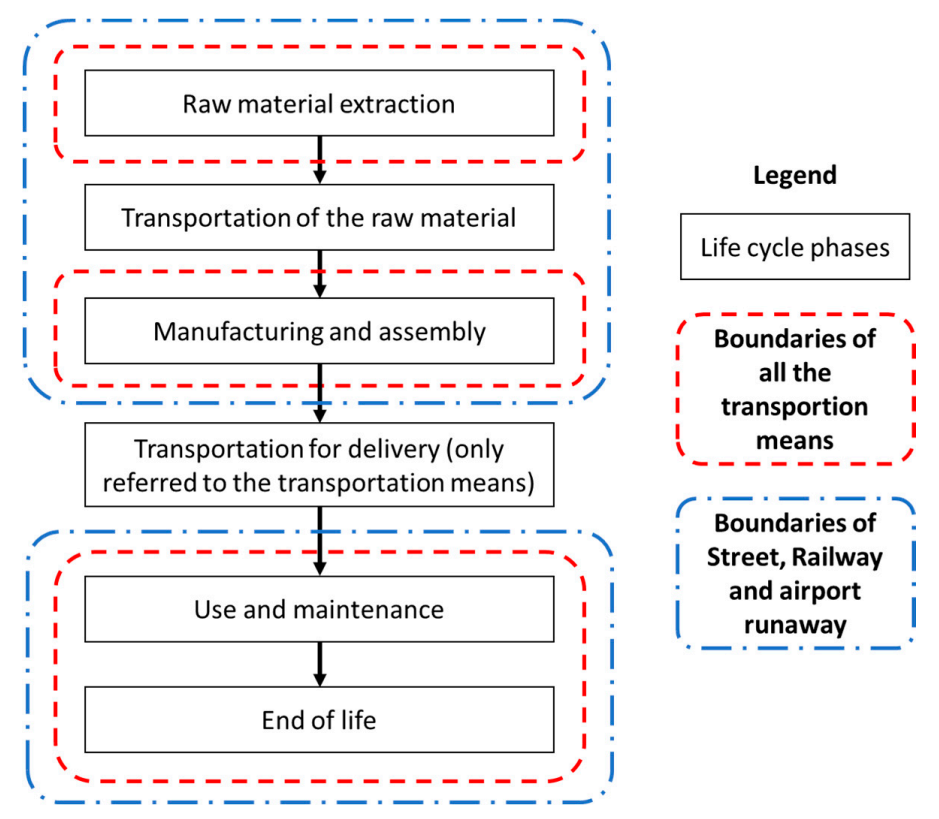

Figure 2. Representation of the system boundaries. The considered items are included within the squares with the dashed red lines for all the transportation means and dashed and dotted blue lines for the infrastructures.

\subsection{Impact Calculation Procedure}

A structured methodology was applied to assess the impacts of all the transportation means, during which the life cycle impacts arising from the masses of the materials and the used energy were collected from the selected sources, and, successively, they have been normalized according to the reference parameters of the functional unit, the geographic factors of the considered scenario, and the European electricity mix for the electric vehicles and European fossil fuels distribution network for those having internal combustion. In addition, the impacts were also derived as a function of the average life of each transportation means in relation to the travelled distance, according to the considered literature.

The impact categories for the analysis were selected among the most commonly used in LCA studies about transportation (e.g., [8,34]) in order to allow the comparison: climate change ( $\mathrm{g} \mathrm{CO}_{2}$ eq.), terrestrial acidification $\left(\mathrm{g} \mathrm{SO}_{2}\right)$, and particulate matter formation $\left(\mathrm{g} \mathrm{PM}_{10}\right)$.

\subsection{Identifcation of the Limitations}

Depending on all the methodological choices described so far in this section, this study has some limitations that are presented in this section in relation to the prescribed criteria about data quality of ISO 14040 [21] and ISO 14044 [22].

The time-related coverage of the study is restricted, because all the considered transportation means and their sources are recent. This choice was adopted to better describe the current situation, considering the great variability of environmental performances and the relatively short life span of many transportation means [41]. For this reason, the significance of the achieved outcomes is destined to gradually decrease over the next years if the current trend is confirmed.

The geographical coverage of the study is limited to the EU-28 scenario, in which the most widespread transportation means and infrastructures can be significantly different from those of other areas of the world, also greatly affecting the overall environmental impacts of the scenario [42]. In addition, the provided perspective is quite narrow, as it is levelled on the European average value, and, unless otherwise specified, i.e., within the sensitivity analysis, the comparison is limited to the average features of infrastructural, geographical, and climatic aspects without explaining 
their differences between the regions, which can also be significant [43]. The completeness of the study is also limited by the perspective provided about the ethnographic habits of the considered population. Significant differences can be detected by comparing the preferences and choices about the transportation means of the populations of the European countries, which are also conditioned by their different per capita income and environmental awareness [44].

The technology coverage is affected by the selection of the most common transportation means on the European market and by the restricted number of models considered for each of them that are effectively documented within valuable scientific papers.

\section{Inventory Data}

In this study, the inventory data phase was less onerous than in a common LCA study, as it was not necessary to promptly analyze all the constituent parts or each transportation means or perform experimental campaigns for assessing the environmental impacts. This is because all the data about the environmental impacts arising from the raw material extraction, manufacturing, use, and end-of-life phases were extrapolated from literature and then normalized according to the parameters of the functional unit and the reference infrastructural and environmental scenario in order to actualize the results to the current average European situation about energy generation and distribution and also considering the consumption and wear of vehicles according to typical road and rail routes.

In the rest of the section, the data collected from the literature and used in this study are described in detail.

To assess the environmental impacts per travelled kilometer of the considered vehicles, we collected two types of data from the selected publications (reported in Section 3.1):

1. The overall environmental impacts during the life cycle of each vehicle in terms of global warming potential, terrestrial acidification, and particulate matter formation, along with those of each phase, e.g., pre-manufacturing, manufacturing, use, and end-of-life.

2. The criteria considered by the authors of the respective publications for the determination of these impacts: type and size of the vehicle, total distance travelled during the life cycle, operative use scenario including the geographical characteristics of the route and the energy mix for electric vehicles, and the average carried weight. These last criteria were used to normalize the overall environmental impacts of each vehicle according to the functional unit of this study in order to allow the comparison between them.

In particular, to assess the impacts arising from the energy consumption of the electric vehicles, the specific impact coefficients of the average European (EU-28) electricity mix [45] have been considered. In the current situation, electricity generation by fuel in the EU-28 is: $29 \%$ from renewables, $26 \%$ from nuclear energy, $21 \%$ from coal and lignite, 20\% from natural and derived gas, $2 \%$ from oil, and $2 \%$ from other fuels. Additionally, all the fossil fuel impacts of all transportation means analyzed have been adapted to the current European situation, in relation to their specific impacts data $[46,47]$.

The considered road and rail routes for the transportation means aim to represent the average situation among the different options most widespread in EU-28 in terms of type of route, i.e., urban, interurban, and mixed, and geographical characteristics, e.g., slope, climate, and weather $[8,48]$. This data was used for the normalization of the environmental impacts of the vehicle during the use phase.

\section{Results and Discussion}

In this section, the outcomes are presented and discussed in a structured way by introducing the significant points with respect to the goal and scope definition and in an ordinated sequence, as prescribed by the normative reference. We adopted this approach to allow the readers to gradually comprehend the results, deepening their causes and limitations and focusing on the crucial ones, as prescribed by [21]. First, within the baseline scenario, the average values of the overall environmental 
impacts have been reported in an aggregate way for each type of transportation means, i.e., bicycles, motorcycles, cars, buses, trains, and airplanes, according to the specified functional unit. Successively, a deeper analysis and comparison about the environmental impacts of the different models of transportation means was presented. Then, these results were reported to the EU-28 scenario to calculate the overall impacts of passenger transportation as a function of the total population and the average distribution of the transportation means. In order to verify the completeness and the consistency of the study and to allow the readers to reach their own conclusions in accordance with the goal and scope, the main limitations of each result are discussed in detail, completing the list of theoretical limitations of the methodology presented in Section 3. A sensitivity analysis was introduced to quantify the relevance of the study, which determines the robustness of the results and identifies how much the infrastructural, geographical, and social features affect the environmental impacts of the transportation means. Finally, some improvements related to a better redistribution in the use of the transportation means and their technological updating have been assessed, presented, and discussed in relation to the overall European scenario. In order to draw the key conclusions and make recommendations for the audience, all the results have been discussed in comparison with other previous studies on the argument by highlighting their main differences along with economical, regulatory, and social considerations.

All the presented results, along with those in the graphs, have been calculated, starting from the considered contributions from the literature about each transportation means, described in Section 3.1, and normalized according to the considered functional unit and scenario, as explained in Section 3.5.

\subsection{Baseline Scenario}

The achieved results about the environmental impacts of the transportation means, expressed in $\mathrm{g}$ $\mathrm{CO}_{2}$ eq., $\mathrm{g} \mathrm{SO}$, and $\mathrm{g} \mathrm{PM}_{10}$ and normalized per 1 passenger per $1 \mathrm{~km}(\mathrm{pkm})$ are summarized in Figure 3 in an aggregate manner according to the types of the transportation means by showing the minimum and the maximum impacts arising from their different considered models. This representation was selected because it allows the readers to compare the contributions of the three impacts categories of each transportation means in relation to a common reference, or the functional unit, and to comprehend their variability depending on the models.

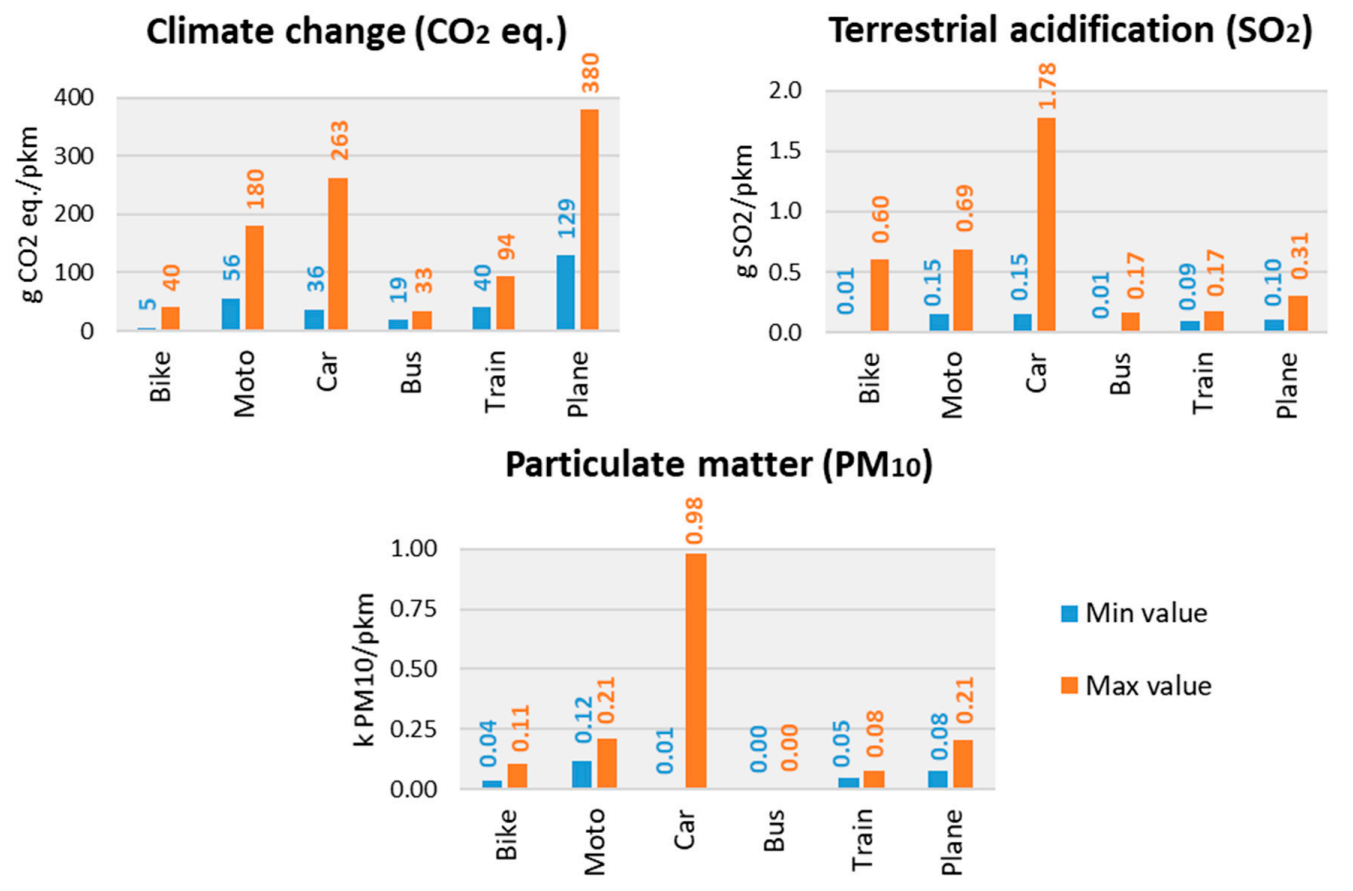

Figure 3. Minimum and maximum values of the environmental impacts of the transportation means. 
The achieved results show that the environmental impacts are between 5 (bicycle) and 380 (airplane) $\mathrm{g} \mathrm{CO}_{2}$ eq./pkm, 0.01 (bicycle and bus) and 1.78 (car) $\mathrm{g} \mathrm{SO}_{2} / \mathrm{pkm}$, and $<0.01$ (bus) and 0.98 (car) $\mathrm{g} \mathrm{PM}_{10} / \mathrm{pkm}$.

The first key observation deals with the predominant role of aircrafts in $\mathrm{CO}_{2}$ eq. impacts and cars for all indicators, especially $\mathrm{PM}_{10}$, compared to other transportation means. As a consequence, it clearly emerges how the public transport is more sustainable than private transport, and on the routes where comparison is possible, that the bus is less impacting than the train and the train than the airplane. In addition, it should be considered that in the case of land-based public transport and rail transport, the infrastructure has a much greater impact than air transport.

The second observation is regarding the considerable variabilities of the impacts for each type of transportation means between the minimum and the maximum value. In order to adequately comment on this aspect and to analyze the distribution of the impacts between the different models, we must move on in the analysis of the results by deepening the contribution of each of them. For this reason, these outcomes are detailed and examined in the rest of the section by maintaining the same order of presentation adopted in Figure 3, i.e., from the bicycle to the airplane, to compare the various types of transportation means also in relation to their size and the typical distance for which they are used.

Figure 4 graphically reports the results about the environmental impacts of all transportation means considered in this study.

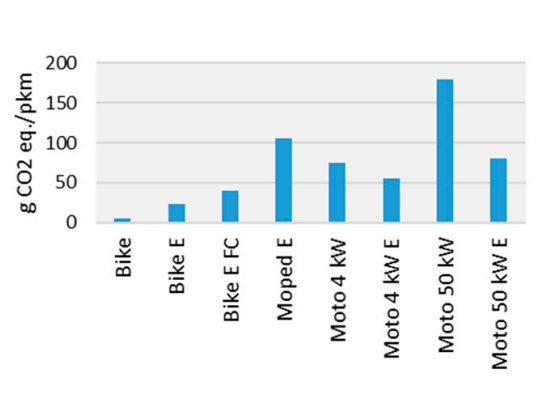

Bicycle and Motorcycle
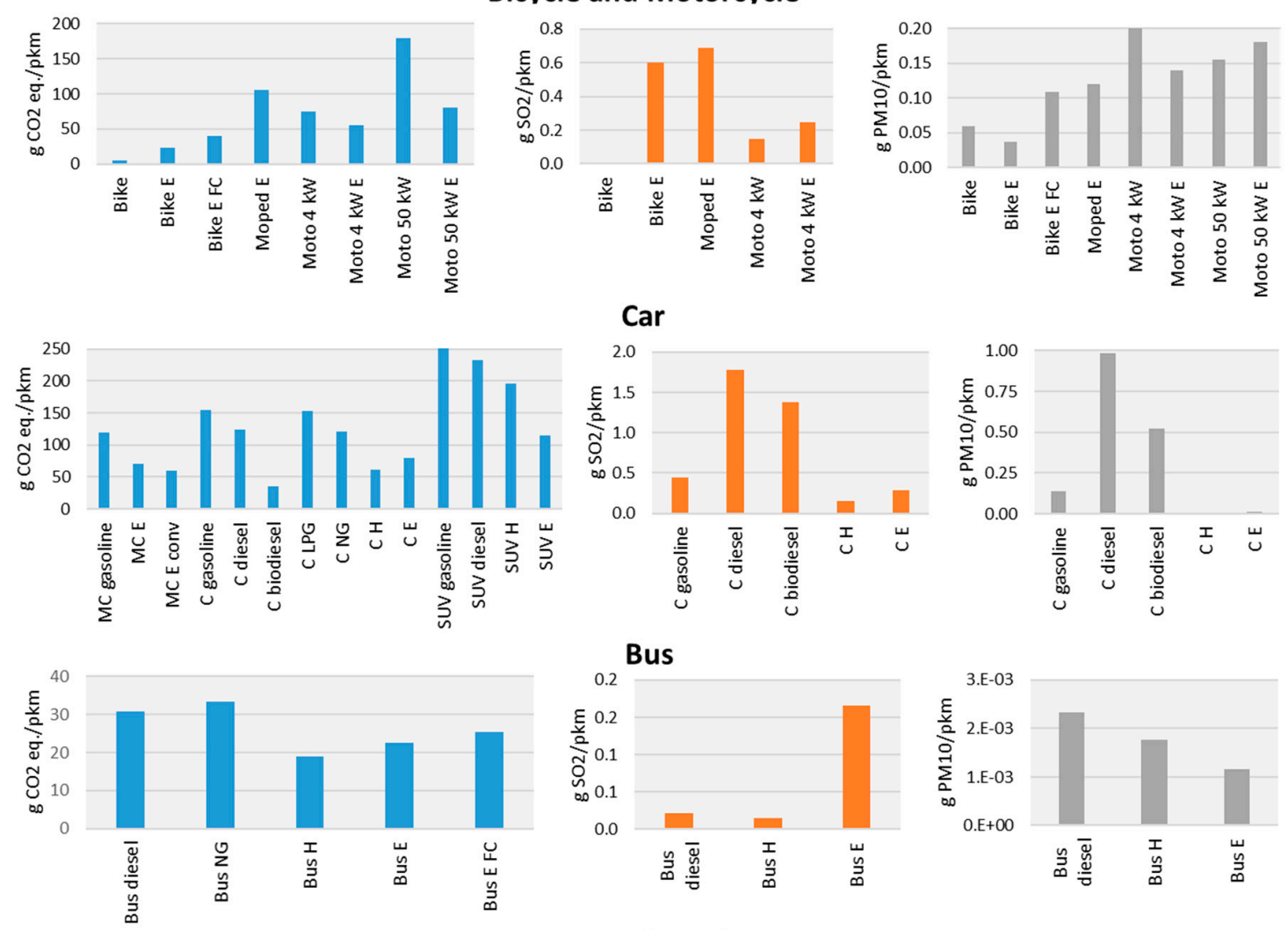

\section{Train and Airplane}
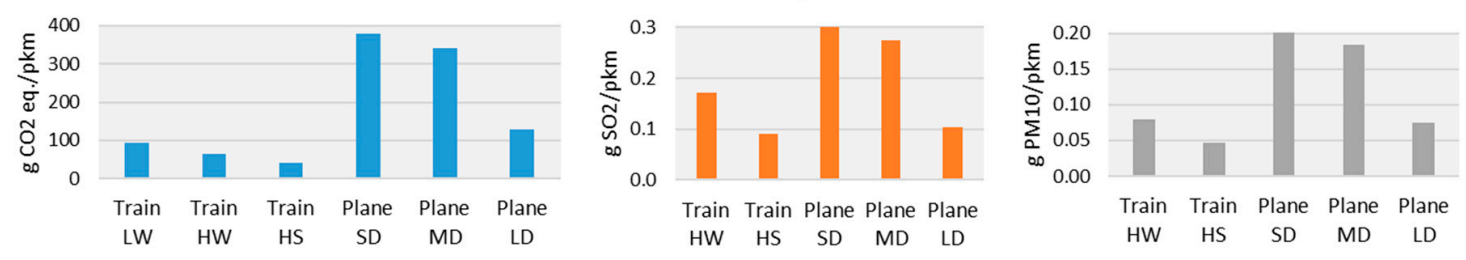

Figure 4. Minimum and maximum values of the environmental impacts of the transportation means. 
By analysing these data, the following considerations can be drawn.

Bicycles are the least impacting transportation means. Among them, the traditional bicycles are the most sustainable with impacts of $4.7 \mathrm{~g} \mathrm{CO}_{2}$ eq./pkm, $0.01 \mathrm{~g} \mathrm{SO}_{2} / \mathrm{pkm}$, and $0.06 \mathrm{~g} \mathrm{PM}_{10} / \mathrm{pkm}$. Electric bicycles, compared to the traditional ones, lead to an increase of the impacts of about $+400 \%$ of $\mathrm{CO}_{2}$ eq. $/ \mathrm{pkm},+800 \%$ of $\mathrm{SO}_{2} / \mathrm{pkm}$, and a reduction of $40 \%$ of $\mathrm{PM}_{10} / \mathrm{pkm}$, with a variability of almost $50 \%$ in the two considered studies of [24] and [10]. Furthermore, fuel cell bicycles further increase $\mathrm{CO}_{2}$ eq./pkm impacts by $+72 \%$ and $\mathrm{PM}_{10} / \mathrm{pkm}$ by about $+200 \%$ compared to electric bicycles.

These results are confirmed by other studies in the literature also related to other areas of the world. Among them, according to [49], electric bicycles emit several times lower pollution per kilometer than motorcycles and cars, and they have comparable emission rates to buses and higher emission rates than bicycles. This is also due to lead, which is one pollutant on which electric bicycles perform poorly because of their use of lead acid batteries.

Due to their sustainability, many cities in Europe and around the world are implementing various interventions to promote and increase their use, with the construction of dedicated infrastructure and both public and private bike sharing. The latter made it possible to save 25,240 t $\mathrm{CO}_{2}$ eq., $64 \mathrm{t} \mathrm{NO}_{\mathrm{x}}$, and $8358 \mathrm{t}$ of petrol in one year in the city of Shanghai, according to the analysis carried out by [50]. Even economically, cycling and bike sharing are cheaper than buses and trains in several cities around the world, at least in the urban scenario [51]. However, the spread of cycling still remains too limited in Europe, where there is no evidence that bike sharing significantly reduces traffic congestion, carbon emissions, and pollution, and the achieved benefits are unequally distributed, as users are typically male, younger, and in more advantaged socio-economic positions than average [52].

Motorcycles have considerably higher impacts than bicycles, especially in terms of $\mathrm{CO}_{2}$ eq./pkm. Among the considered models, it was found that the increase in $\mathrm{CO}_{2}$ eq. impacts is directly related to the power of the vehicle, with $50 \mathrm{~kW}$ models having an average impact of $97 \%$ more than $4 \mathrm{~kW}$ models, and to the type of power supply, with electric motorcycles having an average impact of $47 \%$ less than internal combustion ones. As far as $\mathrm{SO}_{2}$ is concerned, the situation is the opposite, with electric motorcycles having twice as much impact as internal combustion ones, while in the case of $\mathrm{PM}_{10}$, the results are mixed. The electric moped has high impacts of $\mathrm{CO}_{2}$ eq., and $\mathrm{SO}_{2}$ is also significantly higher than $4 \mathrm{~kW}$ motorcycles. This is due to the poor performance of the engine in relation to the weight transported and therefore to its consumption as well as to its particularly short service life [25].

These data are also confirmed by other studies in the literature, which have also warned about their direct emissions of $\mathrm{CO}, \mathrm{HC}$, and $\mathrm{NO}_{\mathrm{x}}$, which can reach considerable values especially for older models and in South East Asian states such as Vietnam, India, Indonesia, Thailand, Taiwan, and China, where motorcycles make up over $60 \%$ of the passenger vehicle fleet [53].

Cars have considerable environmental impacts albeit with great variability due to the large differences between the many considered models due to their size, power supply, and structural features. In general, the type of power supply plays a key role in reducing impacts, in fact electric and hybrid cars generate on average $36 \%$ less $\mathrm{CO}_{2}$ eq. $/ \mathrm{pkm}, 81 \%$ less $\mathrm{SO}_{2} / \mathrm{pkm}$, and $98 \%$ less $\mathrm{PM}_{10} / \mathrm{pkm}$. The size of the vehicle has a net influence especially on $\mathrm{CO}_{2}$ eq./pkm, with medium-sized cars impacting on average $25 \%$ more than micro cars and SUVs impacting on average about $94 \%$ more than medium-sized cars. In the case of fuel-powered cars, it is important to highlight the negative influence on the environment of diesel cars, which, at the same size, although having an average impact of about $15 \%$ less $\mathrm{CO}_{2}$ eq. compared to gasoline cars, are more than $300 \%$ more impacting in terms of $\mathrm{SO}_{2}$ and $600 \% \mathrm{PM}_{10}$. As regards alternative fuels, $\mathrm{LPG}$ and $\mathrm{NG}$ are comparable to gasoline and diesel as $\mathrm{CO}_{2}$ eq. impacts, respectively, while biodiesel is significantly more sustainable than diesel for all three indicators: $-71 \%\left(\mathrm{CO}_{2}\right.$ eq. $\left./ \mathrm{pkm}\right),-23 \%\left(\mathrm{SO}_{2} / \mathrm{pkm}\right)$, and $-47 \%\left(\mathrm{PM}_{10} / \mathrm{pkm}\right)$. Finally, hybrid cars are characterized by a certain variability of environmental impacts due to their use ratio between electric and thermal power: hybrid medium-sized cars are more sustainable than the electric ones, i.e., $-22 \% \mathrm{CO}_{2}$ eq., $-48 \% \mathrm{SO}_{2},-42 \% \mathrm{PM}_{10}$, while hybrid $\mathrm{SUV}$ s are the worst, i.e., $+70 \%$ in $\mathrm{CO}_{2}$ eq. 
The identified results are also confirmed by previous studies. [54] state, through an empirical analysis, that although electric cars are known for decreasing the production of $\mathrm{CO}_{2}$ eq. more than any other option, grid-independent hybrid electric vehicles can be more sustainable than the electric cars when using coal-fired electricity.

Platt et al. [55] confirmed instead the results about diesel and gasoline cars, by stating that the modern models of the first are actually able to reduce the emission of $\mathrm{CO}_{2}$ eq. compared to the second, especially due to the introduction of advanced particulate filters and other optimized fuel injection measures, although they are still considerably worse for the other indicators.

The main limitation of these data lies in their levelling to the European average value, which fails to highlight the differences and peculiarities typical of individual states. In this perspective, the data obtained point toward the progressive elimination of diesel and the electrification of the car fleet throughout Europe and are also supported by studies that consider a narrower perspective, such as [9], which estimated a further $4 \%$ reduction of electric cars by 2030 in the Italian scenario, analysing cars of the same size as those considered and relying on the expected improvements in the national electricity mix in accordance with the planned interventions. In line with these considerations, for some years, European, United States, and Canadian governments are promoting the adoption of electric mobility through restrictions to other cars and incentives that have actually led to benefits on local impact indicators [56]. Additionally, from the economic point of view, electric cars are competitive compared to others, both in purchase and use, thanks mainly to government incentives that have favored growing investments of manufacturers, although with a certain variability between countries due to the national electricity power plant portfolio [57]. However, despite the economic competitiveness, the adoption of ECs is still very low and mostly limited to customers with strong environmental awareness, mainly due to the reduced presence of charging stations on the territory, especially in some EU countries such as Italy [58].

Buses have generally proved to be the most sustainable alternative based on the considered indicators. Among them, the electric or hybrid alternatives are the best, albeit with due considerations. In fact, electric buses, compared to internal combustion ones, are on average $25 \%$ less impacting in terms of $\mathrm{CO}_{2}$ eq./pkm, and about half as impacting in terms of $\mathrm{PM}_{10} / \mathrm{pkm}$, but they are almost 8 times more impacting for $\mathrm{SO}_{2} / \mathrm{pkm}$, while hybrid ones are slightly less impacting than internal combustion ones for $\mathrm{CO}_{2}$ eq. and $\mathrm{SO}_{2}$, and they represent a compromise solution for $\mathrm{PM}_{10}$ emissions.

These data are also confirmed by other studies in literature: [59] demonstrated how, in Norway, the adoption of electric public buses was effective to reduce environmental impacts on local scale. In addition, it was found that the measures undertaken to encourage public transport, with public incentives and restrictions on the circulation of cars at certain times and especially in urban centers, have proved useful in increasing the spread of buses and reducing environmental impacts [60]. In addition, in many European cities, there is a greater economic convenience of the bus compared to the car, and thanks to the increase in overall quality of service, service production, transfer quality, ticket services, and environmental consciousness, a growing number of people shifted to public transportation [61].

Trains proved to be a very sustainable means of transport and partly worse than buses, although a great part of their use is intended to cover significantly longer distances and in less time. In terms of $\mathrm{CO}_{2}$ eq./pkm, it has been found that as the train's size, power, and route increases, the impacts decrease significantly: the HW train impacts on average $30 \%$ less than the LW train, and, in turn, the HS train impacts $39 \%$ less than the $\mathrm{HW}$ train. The impact of $\mathrm{SO}_{2} / \mathrm{pkm}$ also decreases, with the HS train impacting $47 \%$ less than the HW train, and with it, that of $\mathrm{PM}_{10} / \mathrm{pkm}(-41 \%)$.

On urban routes where the train is a direct competitor of the bus, it was found that the first (LW train) has a significantly greater impact than the average impact of all buses $\left(+257 \% \mathrm{CO}_{2} \mathrm{eq} / \mathrm{pkm}\right)$. This can also be partly justified by the significantly greater impact of railway infrastructure compared to road infrastructure. In buses, the impact of road infrastructure accounts for about $0.5 \%$ of the total, while in the LW train, rail accounts for $20 \%$, also due to underground excavations in the case of the 
metro [23]. As train size increases and excavations are reduced, infrastructure impacts fall by up to $8 \%$ (in $\mathrm{CO}_{2}$ eq. $/ \mathrm{pkm}$ ), despite the fact that $\mathrm{HS}$ trains require a rail that is on averagely more impacting than $\mathrm{HW}$ trains with an increase of about $70 \%$ in $\mathrm{CO}_{2}$ eq./pkm in maintenance [8]. In addition, the increased flexibility of private vehicles can also bring other environmental benefits, especially in relation to energy demand. A comparative analysis between electric private vehicles and trains in urban areas in New Zealand, carried out by [62], showed that, despite the overall power demand of the electric vehicles being higher than the train's for every $\mathrm{km}$ travelled by a single passenger, demand side management methods would allow shifting electric vehicles to charging in off-peak time, whereas the train would still contribute significantly more to peak load.

Aircrafts are characterized by a great variability of environmental impacts, which are inversely proportional to the increase in size and travelled distance. MD airplanes impact on average $11 \%$ less on all three indicators than SD airplanes, while LD airplanes, compared to MD airplanes, impact about $62 \%$ less for $\mathrm{CO}_{2}$ eq./pkm and $\mathrm{SO}_{2} / \mathrm{pkm}$ and $59 \%$ less for $\mathrm{PM}_{10} / \mathrm{pkm}$. This is mainly due to the higher operating efficiency of the aircraft used on longer routes both in terms of engines and structure and lower consumption due to the lower number of take-offs or increased use at a higher flight altitude [15].

In the light of these considerations, at present, the comparison between aircraft and high-speed trains on the same distances $(500-1000 \mathrm{~km})$, where they are in direct competition for overall travel costs and times, is clearly favorable for trains considering all three impact indicators, with reductions between $-850 \%$ and $-750 \%$ of $\mathrm{CO}_{2}$ eq. $/ \mathrm{pkm},-230 \%$ and $-200 \%$ of $\mathrm{SO}_{2} / \mathrm{pkm}$, and $-330 \%$ and $-280 \%$ of $\mathrm{PM}_{10} / \mathrm{pkm}$. This fact is also confirmed by [63], which compared the impacts of the two transportation means on the London-Paris route, determining that the $\mathrm{CO}_{2}$ eq./pkm impact of the plane is six times higher than that of the train, although the first one is better for the local air pollution.

These data also find further confirmation in older studies, e.g., [64], which suggest that, despite the efforts made in the aviation sector to increase sustainability, it still pays a substantial delay in this sense toward high-speed trains.

However, both economically and in terms of personal preferences, there is still a lot of competition between trains and airplanes, as shown by several surveys and market analyses on different European routes. For this reason, schedule coordination to reduce connecting time could be crucial to making it possible to combine trains and planes, especially in trips with one or more stopovers, reducing the use of the plane only for longer routes and overflights over the sea [65].

\subsection{Overall European Scenario}

The impacts of the overall European (EU-28) scenario were obtained through the sum of the total contributions of the different transportations means at the community level.

To obtain these data, the environmental impacts normalized per passenger and per $\mathrm{km}$ of each transportation means, obtained in this study and presented in Section 5.1, were multiplied by the total number of $\mathrm{km}$ travelled by all EU-28 passengers using the same transportation means in 1 year, which in turn were obtained from [66-68].

Figure 5 shows the considered distribution of the individual average annual distance travelled by each transportation means in EU-28. It is dominated by cars with $73 \%$ of total use and almost exclusively those fuelled by gasoline and diesel, respectively, in equal measure, followed by airplanes (10\% of the overall), buses (9\%), and trains $(7 \%)$.

Figure 6 shows the environmental impacts of the overall EU-28 scenario in relation to the three indicators considered in this study (i.e., global warming potential, terrestrial acidification, and particulate matter formation), reporting for all of them both the overall impacts per travelled kilometer (in $\mathrm{t} / \mathrm{km}$ ) and the individual impacts per travelled kilometer (in $\mathrm{g} / \mathrm{pkm}$ ) and by showing the percentage distribution of the impacts between the different transportation means. 


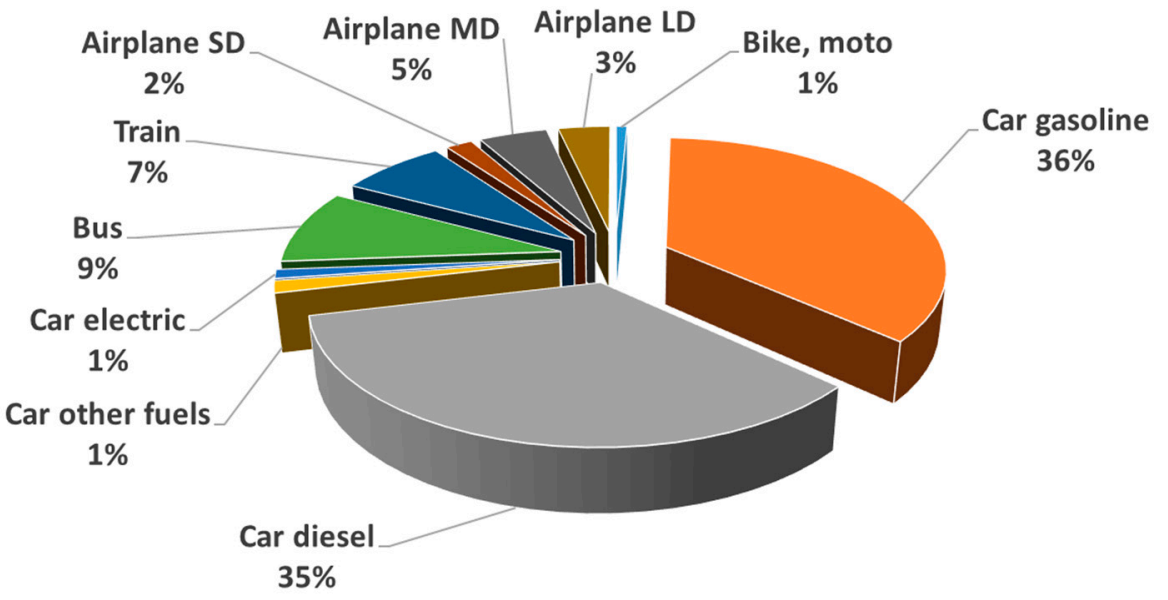

Figure 5. Distribution of the individual average annual distance travelled per transportation means in EU-28, derived from [66-68].

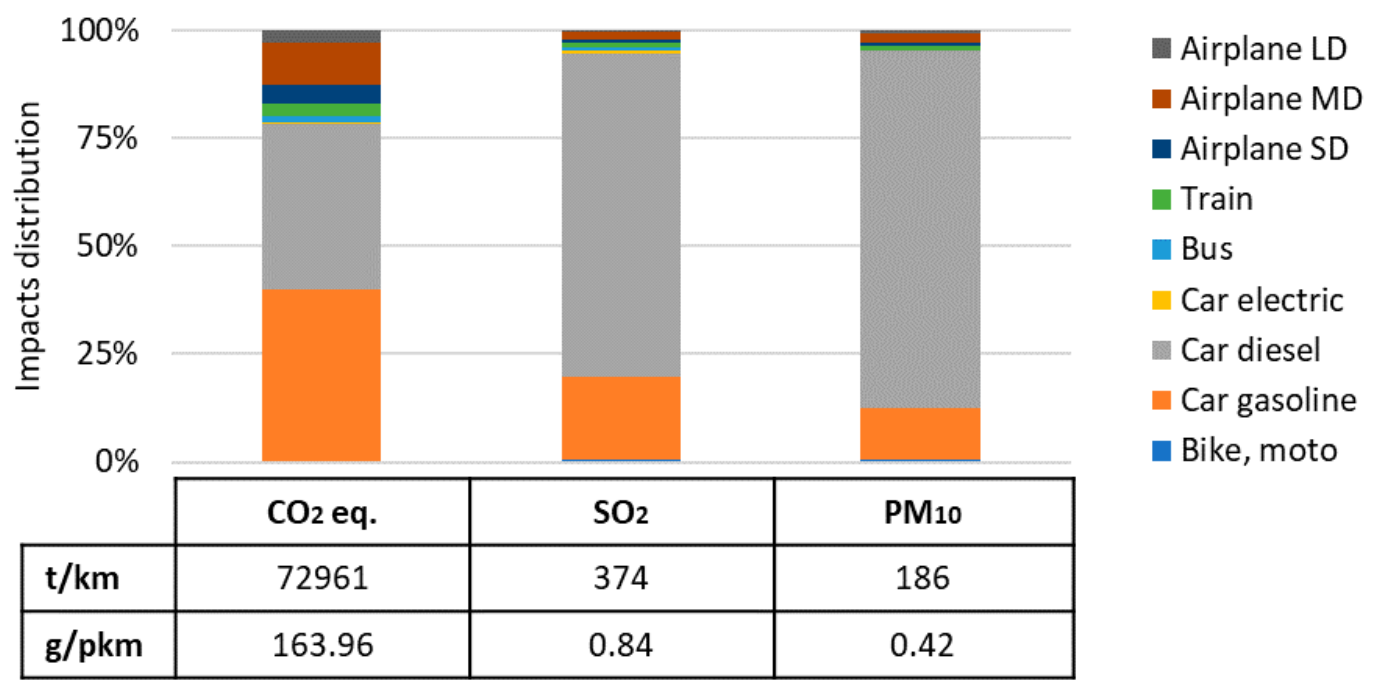

Figure 6. Environmental impacts values and distribution of the overall European (EU-28) scenario between the considered transportation means.

The overall impacts are 72,961 t $\mathrm{CO}_{2}$ eq. $/ \mathrm{km}, 374 \mathrm{t} \mathrm{SO} 2 / \mathrm{km}$, and $186 \mathrm{t} \mathrm{PM}_{10} / \mathrm{km}$. Among them, the impacts of cars constitute the vast majority in all three indicators considered: in the case of $\mathrm{CO}_{2}$ eq. $/ \mathrm{km}$, they are over $78 \%$, while they increase for $\mathrm{SO}_{2} / \mathrm{km}$ by $94 \%$ and for $\mathrm{PM}_{10} / \mathrm{km}$ by $95 \%$. In particular, diesel cars are the most impacting in all three indicators with $37 \%$ of $\mathrm{CO}_{2}$ eq. $/ \mathrm{km}, 73 \%$ of $\mathrm{SO}_{2} / \mathrm{km}$, and $81 \%$ of $\mathrm{PM}_{10} / \mathrm{km}$. Furthermore, aircraft have a considerable percentage impact only in the case of $\mathrm{CO}_{2}$ eq. $/ \mathrm{km}$ : more than $16 \%$ overall.

These data provide an important clarification of those previously presented in Section 5.1. In fact, although the high impacts of cars, and in particular diesel cars for $\mathrm{SO}_{2}$ and $\mathrm{PM}_{10}$, had already been highlighted, the overall EU-28 scenario shows much more clearly their role, even in the case of $\mathrm{CO}_{2}$ eq., due to the extremely high overall use of cars compared to other means of transport, as shown in Figure 5. This result is also confirmed by other studies in the literature, which report that at the European level, diesel cars are also responsible for excessive amounts of $\mathrm{NO}_{x}$ and $\mathrm{PM}_{2.5}$, which have a high correlation with various clinical diseases and premature deaths [69].

From this point of view, the outlook for the future is very uncertain. On the one hand, in recent years there has been a consistent reduction in the environmental impacts of cars, even though the long 
term EU proposals, expected in the five-year period 2020-2025 to reduce impacts up to $68-78 \mathrm{~g} \mathrm{CO}_{2}$ eq./km have been partly scaled down and postponed [70]; on the other hand, we have witnessed an increase in electric cars, although still too contained both in relation to the ideal values to meet the targets set and in comparison with the overall increase in registered cars and their greater use against other transportation means such as buses and trains [71].

The overall percentage of flights in EU-28 is also growing, especially due to low-cost offers, although in short distances and on several routes, trains have reached up to $70 \%$ of preferences [63]. Forecasts for the future confirm this trend, and several modernization interventions of the air fleet aimed at reducing environmental impacts, especially with regard to $\mathrm{CO}_{2}$ eq. and energy expenditure, have been planned through the introduction of more efficient engines and lighter materials [15].

\subsection{Sensitivity Analysis}

The sensitivity analysis of the environmental impacts was conducted by considering the variation of the number of passengers in public transport, the electricity mix, and the vehicle use distribution, where the second and the third, respectively, consider the real values about electricity mix and vehicle distributions of the three European biggest countries, i.e., France, Germany, and Italy, which together amount to almost half the total population of the EU-28. These variations were explored to provide an assessment of the variability of the main parameters on which this study is based.

\subsubsection{Variations of the Number of Passengers}

Figure 7 summarizes the main findings about the variation of the number of passengers. These data express the environmental break-even points given by the minimum percentage passenger capacity of public transport, compared to the European average value, so that the latter have the same impact as the average of cars, according to the three considered indicators. The comparison with cars was considered because they are the most diffused transportation means, while the vehicles for the public transport are those that typically compete with cars; for this reason, LD airplanes, which do not have long distance competitors, were excluded from the analysis.

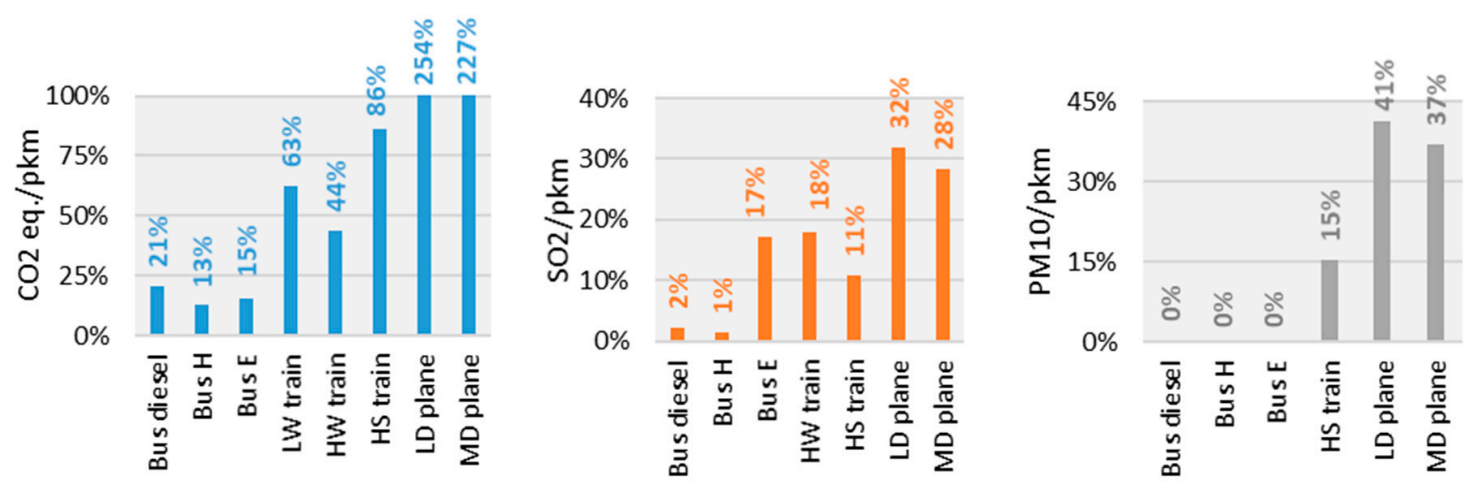

Figure 7. Filling coefficients of the public transportation means, compared to the average capacity, to balance the average environmental impacts of cars.

Analysing the results showed in Figure 7, it emerges that buses are the transportation means that guarantee the lowest impacts even with a very low occupancy, which can get off below 11 passengers to balance the $\mathrm{CO}_{2}$ eq./pkm of the cars (in the case of the diesel bus), 10 passengers for the $\mathrm{SO}_{2} / \mathrm{pkm}$ (electric bus), and 1 passenger for the $\mathrm{PM}_{10} / \mathrm{pkm}$ (all buses). Airplanes represent the most unfavorable situation, especially in the case of $\mathrm{CO}_{2}$ eq./pkm, where the theoretical capacity should be about 2.5 times the current one to balance the value of the average impact of cars, while the values are much lower for the other indicators. Finally, trains represent an intermediate situation, and they maintain a certain 
sustainability even with a wide passenger variability, even if it is reduced only up to $14 \%$ compared to the average capacity value, in the case of $\mathrm{CO}_{2}$ eq./pkm for $\mathrm{HS}$ trains.

\subsubsection{Variations of the Electricity Mix}

Figure 8 shows the main findings about the variation of the electricity mix on the impacts of the transportation means, showing the $\mathrm{g} \mathrm{CO}_{2}$ eq./pkm, to which this analysis is limited, of each electric transportation means in EU-28 (already reported in Section 5.1), France, Germany, and Italy. The values of the specific impacts of the electricity mix of the three countries were considered equal to $57.6 \mathrm{~g} \mathrm{CO}_{2}$ eq./kWh in France, $439.2 \mathrm{~g} \mathrm{CO}_{2}$ eq./kWh in Germany, and $255.6 \mathrm{~g} \mathrm{CO}_{2}$ eq./ $/ \mathrm{kWh}$ in Italy, according to [45].

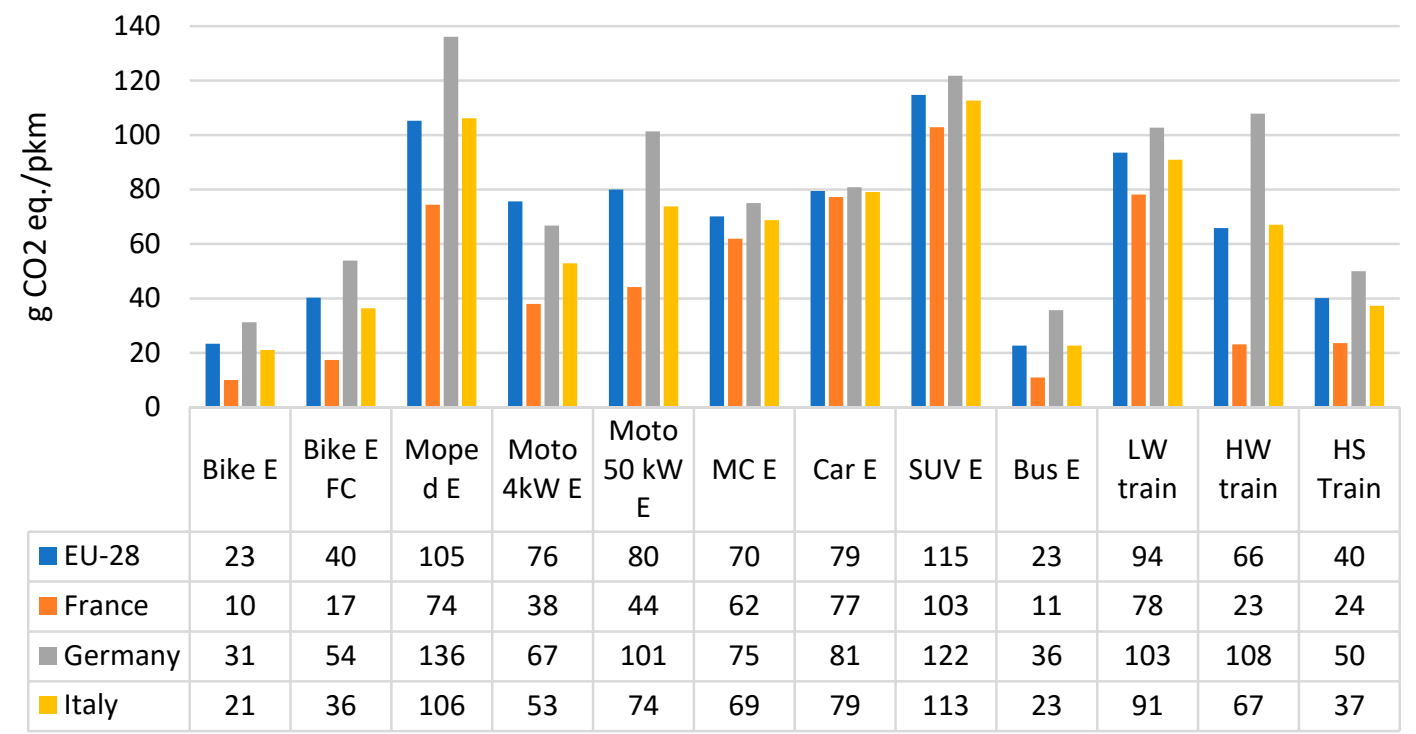

Figure 8. Environmental impacts ( $\mathrm{g} \mathrm{CO}_{2} \mathrm{eq} . / \mathrm{pkm}$ ) of the electric vehicles in EU-28 (blue), France (orange), Germany (grey), and Italy (yellow).

Analysing the results showed in Figure 8, it emerges that the change in the electricity mix substantially affects the impacts, with an average change in the impacts of all electric vehicles of $33 \mathrm{~g}$ $\mathrm{CO}_{2}$ eq./pkm, equal to $124 \%$, moving from Germany (worst case) to France (most favorable case). These data clearly reward France and disadvantage Germany because of their respective electricity mixes, resulting in specific impacts, which in these two countries are $80 \%$ lower and $47 \%$ higher than the European average, respectively, for each $\mathrm{kWh}$ of electricity produced. At the level of the single transportation means, the electricity mix has a higher percentage effect for the HW train, with a $365 \%$ difference between Germany and France, electric bus (226\%), and electric bike $(210 \%)$, while in absolute terms for the $\mathrm{HW}$ train has a $85 \mathrm{~g} \mathrm{CO}_{2}$ eq./pkm difference between Germany and France, electric moped (62 $\mathrm{g} \mathrm{CO}_{2}$ eq./pkm), and electric motorcycle $50 \mathrm{~kW}\left(57 \mathrm{~g} \mathrm{CO}_{2}\right.$ eq./pkm).

\subsubsection{Variations of the Vehicle Use Distribution}

The main results on vehicle use distribution variation are summarized in Figure 9. The graphic representation of the results is the same as Figure 6, but the total impacts and their distributions refer to France, Italy, and Germany. The distributions concerning the frequencies of use of the transportation means in the single countries were derived from [66-68]. Substantial differences in the three cases refer to the different use percentages of gasoline and diesel cars, which are $22 \%$ and $49 \%$ in France, $47 \%$ and $24 \%$ in Germany, and $36 \%$ and $31 \%$ in Italy, respectively. 


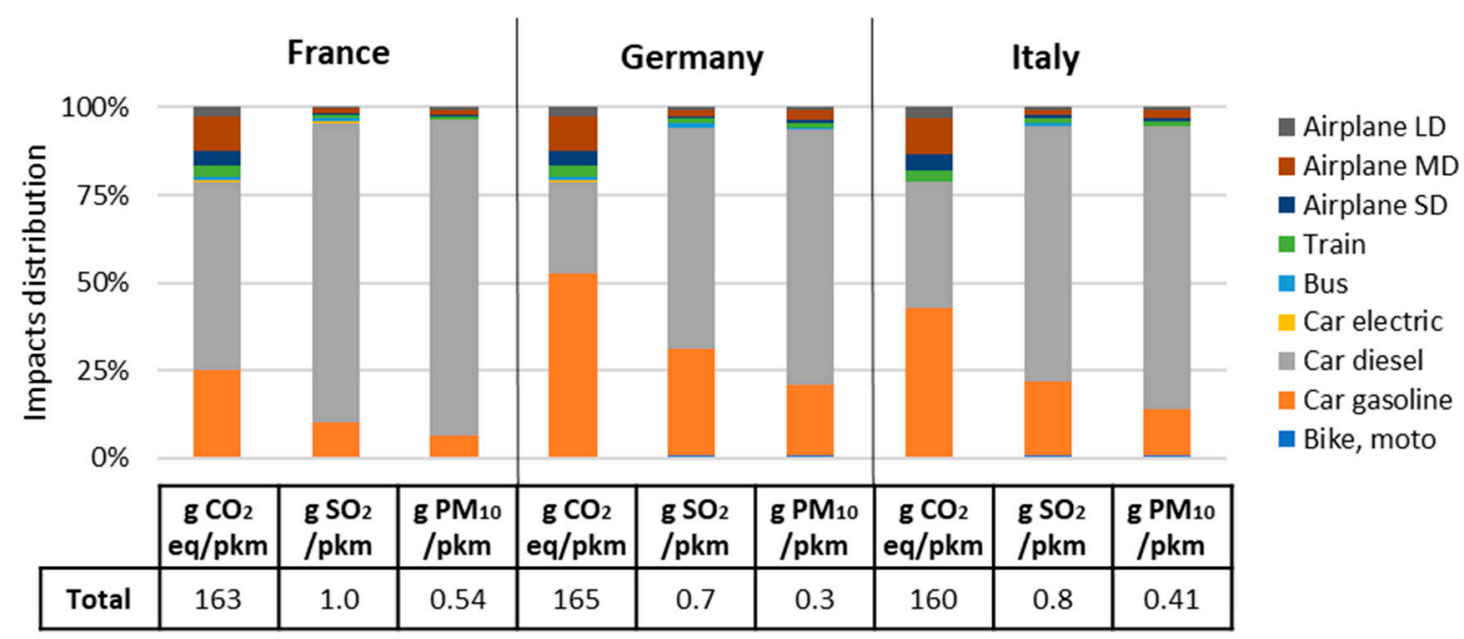

Figure 9. Average environmental impacts distributions (in pkm) of the transportation means in France, Germany, and Italy.

Analysing the results showed in Figure 9, it emerges that, with regard to the average generation of $\mathrm{CO}_{2}$ eq./pkm, the three countries are substantially aligned with the European average $(-0.1 \%$ France, $+0.4 \%$ Germany, and $-2 \%$ Italy), while the differences are more marked in the case of $\mathrm{SO}_{2} / \mathrm{pkm}(+22 \%$ France, $-16 \%$ Germany, and $-0.32 \%$ Italy) and in the case of $\mathrm{PM}_{10} / \mathrm{pkm}$ (+28.5\% France, $-31 \%$ Germany, and $-3 \%$ Italy). The results clearly reward Germany at the expense of France, mainly due to the percentage of reduction of diesel cars compared to the total, while Italy is in an intermediate situation and it is substantially aligned with EU-28 results.

\subsection{Improvements}

In this section, a selection of improvements from the literature for reducing the impacts of mobility are evaluated, compared, and discussed in relation to the overall EU-28 scenario. Depending on the results obtained in Section 5.2, the proposed improvements are more focused on reducing car impacts.

The first three improvements act specifically on the redistribution of car types according to their power supply, taking into account the European minimum and maximum values from [68]. The first and the second concern the reduction of the percentage of use of diesel cars to $26 \%$ of the entire car fleet, as in Finland, and 0\%, as experienced from time to time in some European cities, and their replacement by gasoline cars. The third improvement investigates the effect of the increase in the diffusion of electric cars up to the current world maximum value, i.e., 9.3\% of total cars as in Norway.

The fourth improvement concerns the structural improvement of gasoline cars by lightening the overall mass of the chassis and other parts of the car [72]. Although this hypothesis was tested by the same authors only for turbocharged gasoline cars, it was considered to extend it to all gasoline-powered models of this study, considering, as a precautionary measure, the minimum value of the benefits presented by the authors.

The fifth improvement concerns the increase in the use of buses and trains to their maximum levels in EU-28, i.e., $20 \%$ and $10 \%$ of the total, respectively [67], dividing these values proportionally between their models and reducing the percentage of car use to $30 \%$ of the total.

The sixth improvement concerns the widespread adoption of high-speed trains to replace other types of trains, including for short distances, as is already happening in other parts of the world, e.g., Shanghai (China), to connect different areas of the city or the downtown area to the airport, and for medium distances, with the increase in the number of HS train stops also in secondary cities and the increased use by regional commuters, as is happening in Spain, France, and Germany [73]. The hypothesis in this case is that the impacts of HS trains remain unchanged even with the substantial reduction of distances typically travelled. 
Finally, the last improvement concerns the updating of the entire airline fleet, with the adoption of the most modern aircraft for SD, MD, and LD that make extensive use of light materials to reduce energy consumption, as planned for the period 2030-2050 [15]. This improvement was evaluated in relation to the average $\mathrm{CO}_{2}$ eq. $/ \mathrm{km}$ reduction of about $15 \%$ for each aircraft as reported by the authors themselves.

In order to compare the proposed improvements, Figure 10 reports graphically and textually their saved environmental impacts for the overall EU-28 scenario, normalized for the distance covered of $1 \mathrm{~km}$.

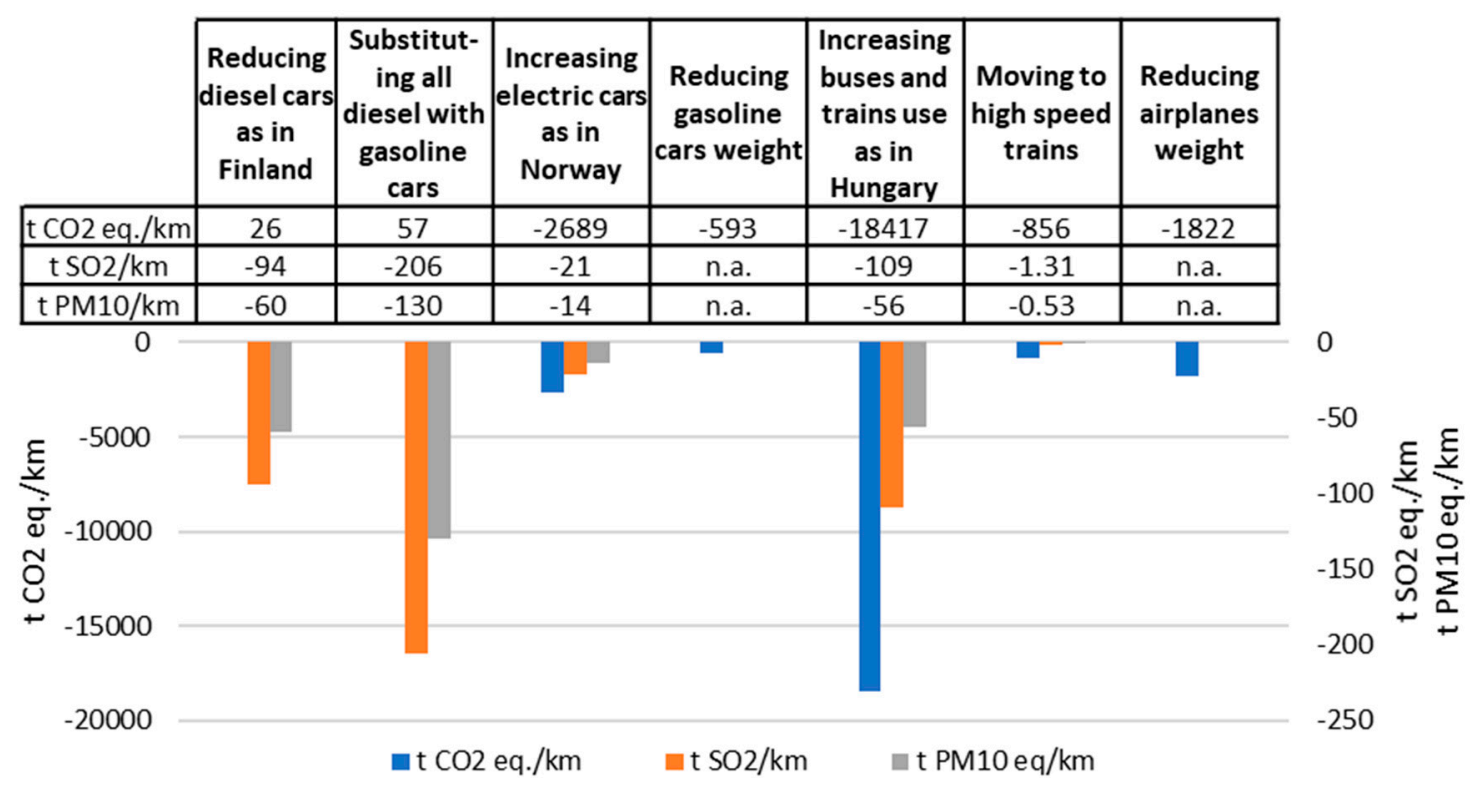

Figure 10. Comparison of the improvements in the EU-28 scenario.

Analysing the results showed in Figure 10, we can see how the improvements have different benefits on the considered environmental indicators. For what concerns the $\mathrm{CO}_{2}$ eq. reduction, the increase in the use of public transport, as in Hungary, leads to the greatest benefits in absolute terms, followed by the increased adoption of the electric cars, as in Norway, while the other measures lead to considerably reduced benefits and require significantly longer implementation times. Moreover, the first two interventions are objectives already achieved in the two respective countries, and others (e.g., Sweden) are not very far from them, although these countries are characterized by a low population. As far as the reduction of $\mathrm{SO}_{2}$ and $\mathrm{PM}_{10}$ is concerned, the total elimination of diesel cars (i.e., second improvement) plays a crucial role and leads to considerable benefits, which can be achieved to a large extent, i.e., 46\%, even with the partial reduction, as in the case of Finland (i.e., first improvement). This is followed by the advantages of using public transport (i.e., fifth improvement).

The obtained outcomes are also confirmed by different previous studies carried out in other contexts and operational scales. Both [74] and [75] highlighted the advantages in terms of environmental impacts reduction arising from an increased use of buses to the detriment of private cars in Malaysia and Sweden, respectively, albeit with different proportions mainly due to the types of vehicles most diffused in the two countries. [76] confirmed the advantages achievable by replacing diesel cars on a large scale with electric ones, obtaining a result that, although limited to the case of Denmark, can be compared to ours about the European scenario, making the due proportions in relation to the number of vehicles. Finally, the work of [77] confirmed the results about the substitution of the diesel cars with the gasoline ones in relation to a study in China, also referable to ours in proportion.

Thus, considering these data, it is therefore believed that the implementation in the near future of the Paris Climate Agreement Goals [66], especially the part related to transportation, could lead 
to significant benefits to environmental sustainability, especially with the substantial reduction of diesel cars, the promotion of more widespread and efficient public transport, and the increase of electric private and public transportation. This comparison does not exclude the implementation of the other improvements, although at present, and in relation to the former, they are significantly less advantageous in environmental terms.

\section{Conclusions}

This study presents a LCA based on global warming potential, terrestrial acidification, and particulate matter formation of all the most diffused transportation means commonly used in the EU-28 scenario by exploiting only sources from scientific literature. The functional unit and other assumptions for the study were defined in relation to the climatic, infrastructural, and ethnographic habits of the considered scenario.

All the main outputs of this work were graphically and textually reported and discussed. They compare the impacts of the transportation means, in relation to the type (car, train, plane, etc.), the specific variants about energy sources (e.g., electric car vs diesel car), and size/power (e.g., microcar vs SUV), where the data about each vehicle are obtained by considering different models. The impacts of the single vehicles have then been combined to obtain the overall impacts about passenger transportation in Europe, considering the average use frequencies of the transportation means, in terms of choice and frequency, of the overall population. They also show the variations of the impacts deriving from a sensitivity analysis, and they compare the impacts reductions deriving from some common improvements regarding a better selection of the transportation means and technical improvements.

In conclusion, the proposed study provided all the elements for a rough quantification of the impacts of the transportation means and the aggregate value at the European level: airplanes have the highest impacts of $\mathrm{CO}_{2}$ eq./pkm, while cars have the highest impacts of $\mathrm{SO}_{2} / \mathrm{pkm}$ and $\mathrm{PM}_{10} / \mathrm{pkm}$; overall, cars account for almost all impacts of the EU-28; the greatest advantages were achieved by adopting more buses and trains and reducing the number of diesel cars.

The achieved outcomes also made it possible to answer the initial hypotheses, considering the limitations of the study in relation to the assumptions made during the selection of the transportation means, the definition of the functional unit and the operative scenario, the considered sources and methods, and the evaluation of the results limited to the three considered environmental impact indicators. (Hypothesis 1) The different types of means of transport, the power supply, size and power, and the model have a significant influence on environmental impacts, as well as the filling coefficient of public transport and, for the electric ones, the electricity mix of the various countries. (Hypothesis 2) The population's habits about transportation strongly affect the overall impacts, especially in relation to the distribution of the types of cars, especially those based on diesel and gasoline engines. (Hypothesis 3) The analyzed selections of the transportation means and the technical improvements can effectively reduce the overall impacts, especially for what concerns the redistribution of the use frequency of the types of cars.

The answers to the hypotheses lead to some common implications for legislators, manufacturers, and users in order to improve environmental awareness about transportation:

Public transport should be more supported, with attention given particularly to buses for urban transport, while short range planes should be limited in favor of greater use of high-speed trains, which are considerably more sustainable.

Electric mobility should be further boosted for each kind of vehicle, as it can represent an alternative to fossil fuels in different operative contexts, even where electricity mixes are less advantageous.

The users should be better informed and supported during the purchase of the cars with regard to their sustainability, especially in relation to the responsibility arising from the type of power supply and the size of the vehicle. In the transition period toward full electric mobility, diesel cars should be limited in favor of hybrid cars or gasoline models. 
In relation to the European scenario, substantial attention should be paid to cars, because of their very widespread and frequent use, especially diesel cars, and secondly to air transport. The improvements ensuring the greatest reductions in environmental impacts are those that reduce the use of cars in favor of public transport (i.e., buses and trains) and those that change their distribution, increasing the use of electric cars and possibly gasoline cars instead of diesel ones.

In the future, further evaluations could be made by enlarging the perimeter of the study to other types and models of transportation means by enlarging the proposed evaluation to other environmental indicators and introducing deeper economic considerations for the evaluation of the alternatives.

Author Contributions: Conceptualization: C.S. and D.R.; methodology: C.S.; validation: C.S.; formal analysis: C.S.; investigation: C.S.; resources: C.S.; data curation: C.S.; writing-original draft preparation: C.S.; writing-review and editing: C.S. and D.R.; visualization: C.S.; supervision: D.R.; project administration: D.R.; funding acquisition: D.R. All authors have read and agreed to the published version of the manuscript.

Funding: This research received no external funding.

Conflicts of Interest: The authors declare no conflict of interest.

\section{References}

1. International Energy Association. Summary for Policymakers. 2014. Available online: https://www.ipcc.ch/ site/assets/uploads/2018/02/ipcc_wg3_ar5_summary-for-policymakers.pdf (accessed on 13 September 2020).

2. Suleiman, A.; Tight, M.R.; Quinn, A.D. Assessment and prediction of the impact of road transport on ambient concentrations of particulate matter PM10. Transp. Res. Part D Transp. Environ. 2016, 49, 301-312. [CrossRef]

3. Khalili, S.; Rantanen, E.; Bogdanov, D.; Breyer, C. Global Transportation Demand Development with Impacts on the Energy Demand and Greenhouse Gas Emissions in a Climate-Constrained World. Energies 2019, 12, 3870. [CrossRef]

4. Litman, T.; Burwell, D. Issues in sustainable transportation. Int. J. Glob. Environ. Issues 2006, 6, $331-347$. [CrossRef]

5. Kellner, F. Generating Greenhouse Gas Cutting Incentives when Allocating Carbon Dioxide Emissions to Shipments in Road Freight Transportation. 2020. Available online: https://ink.springer.com/article/10.1007/ s11367-016-1244-0 (accessed on 13 September 2020).

6. Pehnt, M. Assessing future energy and transport systems: The case of fuel cells. Int. J. Life Cycle Assess. 2003, 8, 283. [CrossRef]

7. Del Pero, F.; Delogu, M.; Pierini, M.; Bonaffini, D. Life Cycle Assessment of a heavy metro train. J. Clean. Prod. 2015, 87, 787-799. [CrossRef]

8. Jones, H.; Moura, F.; Domingos, T. Life cycle assessment of high-speed rail: A case study in Portugal. Int. J. Life Cycle Assess. 2017, 22, 410-422. [CrossRef]

9. Girardi, P.; Gargiulo, A.; Brambilla, P.C. A comparative LCA of an electric vehicle and an internal combustion engine vehicle using the appropriate power mix: The Italian case study. Int. J. Life Cycle Assess. 2015, 20, 1127-1142. [CrossRef]

10. Mellino, S.; Petrillo, A.; Cigolotti, V.; Autorino, C.; Jannelli, E.; Ulgiati, S. A Life Cycle Assessment of lithium battery and hydrogen-FC powered electric bicycles: Searching for cleaner solutions to urban mobility. Int. J. Hydrogen Energy 2017, 42, 1830-1840. [CrossRef]

11. Cox, B.L.; Mutel, C.L. The environmental and cost performance of current and future motorcycles. Appl. Energy 2018, 212, 1013-1024. [CrossRef]

12. Chester, M.V.; Horvath, A. Environmental assessment of passenger transportation should include infrastructure and supply chains. Environ. Res. Lett. 2009, 4, 024008. [CrossRef]

13. Allen, J.; Piecyk, M.; Piotrowska, M.; McLeod, F.; Cherrett, T.; Ghali, K.; Nguyen, T.; Bektas, T.; Bates, O.; Wise, S.; et al. Understanding the impact of e-commerce on last-mile light goods vehicle activity in urban areas: The case of London. Transp. Res. Part D Transp. Environ. 2018, 61, 325-338. [CrossRef]

14. Nordelöf, A.; Messagie, M.; Tillman, A.M.; Söderman, M.L.; Van Mierlo, J. Environmental impacts of hybrid, plug-in hybrid, and battery electric vehicles-What can we learn from life cycle assessment? Int. J. Life Cycle Assess. 2014, 19, 1866-1890. [CrossRef] 
15. Timmis, A.J.; Hodzic, A.; Koh, L.; Bonner, M.; Soutis, C.; Schäfer, A.W.; Dray, L. Environmental impact assessment of aviation emission reduction through the implementation of composite materials. Int. J. Life Cycle Assess. 2015, 20, 233-243. [CrossRef]

16. Bamberg, S.; Schmidt, P. Incentives, morality, or habit? Predicting students' car use for university routes with the models of Ajzen, Schwartz, and Triandis. Environ. Behav. 2003, 35, 264-285. [CrossRef]

17. Helmers, E.; Dietz, J.; Hartard, S. Electric car life cycle assessment based on real-world mileage and the electric conversion scenario. Int. J. Life Cycle Assess. 2017, 22, 15-30. [CrossRef]

18. Johanning, A.; Scholz, D. A First Step towards the Integration of Life Cycle Assessment into Conceptual Aircraft Design; Deutsche Gesellschaft für Luft-und Raumfahrt-Lilienthal-Oberth eV: Bonn, Germany, 2014.

19. Puhe, M.; Schippl, J. User perceptions and attitudes on sustainable urban transport among young adults: Findings from Copenhagen, Budapest and Karlsruhe. J. Environ. Policy Plan. 2014, 16, 337-357. [CrossRef]

20. Van Fan, Y.; Perry, S.; Klemeš, J.J.; Lee, C.T. A review on air emissions assessment: Transportation. J. Clean. Prod. 2018, 194, 673-684. [CrossRef]

21. ISO 14040:2006. Environmental Management_LCA—Principles and Framework; ISO: Geneva, Switzerland, 2006.

22. ISO 14044:2006. Environmental Management_LCA-Requirements and Guidelines; ISO: Geneva, Switzerland, 2006.

23. Chester, M.V. Life-Cycle Environmental Inventory of Passenger Transportation in the United States. Ph.D. Thesis, University of California, Berkeley, Berkeley, CA, USA, 2008.

24. Li, T.Z.; Qian, F.; Su, C. Energy consumption and emission of pollutants from electric bicycles. In Applied Mechanics and Materials; Trans Tech Publications Ltd.: Stafa-Zurich, Switzerland, 2014; Volume 505, pp. 327-333.

25. Hollingsworth, J.; Copeland, B.; Johnson, J.X. Are e-scooters polluters? The environmental impacts of shared dockless electric scooters. Environ. Res. Lett. 2019, 14, 084031. [CrossRef]

26. Leuenberger, M.; Frischknecht, R. Life Cycle Assessment of Two Wheel Vehicles; ESU-Services Ltd.: Uster, Switzerland, 2010.

27. Kerdlap, P.; Gheewala, S.H. Electric motorcycles in Thailand: A life cycle perspective. J. Ind. Ecol. 2016, 20, 1399-1411. [CrossRef]

28. Nanaki, E.A.; Koroneos, C.J. Comparative LCA of the use of biodiesel, diesel and gasoline for transportation. J. Clean. Prod. 2012, 20, 14-19. [CrossRef]

29. Yasar, A.; Haider, R.; Tabinda, A.B.; Kausar, F.; Khan, M. A comparison of engine emissions from heavy, medium, and light vehicles for CNG, diesel, and gasoline fuels. Pol. J. Environ. Stud. 2013, 22, 1277-1281.

30. Lombardi, L.; Tribioli, L.; Cozzolino, R.; Bella, G. Comparative environmental assessment of conventional, electric, hybrid, and fuel cell powertrains based on LCA. Int. J. Life Cycle Assess. 2017, 22, 1989-2006. [CrossRef]

31. Kemp, N.J.; Keoleian, G.A.; He, X.; Kasliwal, A. Life cycle greenhouse gas impacts of a connected and automated SUV and van. Transp. Res. Part D Transp. Environ. 2020, 83, 102375. [CrossRef]

32. Szumska, E.; Pawełczyk, M.; Pistek, V. Evaluation of the Life Cycle Costs for urban buses equipped with conventional and hybrid drive trains. Archiwum Motoryzacji 2019, 83, 73-86.

33. Lajunen, A.; Lipman, T. Lifecycle cost assessment and carbon dioxide emissions of diesel, natural gas, hybrid electric, fuel cell hybrid and electric transit buses. Energy 2016, 106, 329-342. [CrossRef]

34. Cooney, G.; Hawkins, T.R.; Marriott, J. Life cycle assessment of diesel and electric public transportation buses. J. Ind. Ecol. 2013, 17, 689-699. [CrossRef]

35. Chester, M.V.; Horvath, A.; Madanat, S. Comparison of life-cycle energy and emissions footprints of passenger transportation in metropolitan regions. Atmos. Environ. 2010, 44, 1071-1079. [CrossRef]

36. Chester, M.; Horvath, A. High-speed rail with emerging automobiles and aircraft can reduce environmental impacts in California's future. Environ. Res. Lett. 2012, 7, 034012. [CrossRef]

37. Cox, B.; Jemiolo, W.; Mutel, C. Life cycle assessment of air transportation and the Swiss commercial air transport fleet. Transp. Res. Part D Transp. Environ. 2018, 58,1-13. [CrossRef]

38. Yap, M.; Cats, O.; van Arem, B. Crowding valuation in urban tram and bus transportation based on smart card data. Transp. A Transp. Sci. 2020, 16, 23-42. [CrossRef]

39. EN 15663. Railway Applications - Definition of Vehicle Reference Masses; CEN: Bruxelles, Belgium, 2009. 
40. Allacker, K.; Mathieux, F.; Pennington, D.; Pant, R. The search for an appropriate end-of-life formula for the purpose of the European Commission Environmental Footprint initiative. Int. J. Life Cycle Assess. 2017, 22, 1441-1458. [CrossRef]

41. Wanke, P.; Chen, Z.; Zheng, X.; Antunes, J. Sustainability efficiency and carbon inequality of the Chinese transportation system: A Robust Bayesian Stochastic Frontier Analysis. J. Environ. Manag. 2020, 260, 110163. [CrossRef] [PubMed]

42. Alpkokin, P.; Black, J.A.; Iyinam, S.; Kesten, A.S. Historical analysis of economic, social and environmental impacts of the Europe-Asia crossings in Istanbul. Int. J. Sustain. Transp. 2016, 10, 65-75. [CrossRef]

43. Winkel, R.; Weddige, U.; Johnsen, D.; Hoen, V.; Papaefthimiou, S. Shore side electricity in Europe: Potential and environmental benefits. Energy Policy 2016, 88, 584-593. [CrossRef]

44. Focas, C.; Christidis, P. Peak car in Europe? Transp. Res. Procedia 2017, 25, 531-550. [CrossRef]

45. European Environment Agency. Overview of Electricity Production and Use in Europe. 2016. Available online: https://www.eea.europa.eu/data-and-maps/indicators/overview-of-the-electricityproduction-2/assessment-4 (accessed on 13 September 2020).

46. Dong, X.; Wang, B.; Yip, H.L.; Chan, Q.N. CO2 emission of electric and gasoline vehicles under various road conditions for China, Japan, Europe and world average-Prediction through year 2040. Appl. Sci. 2019, 9, 2295. [CrossRef]

47. Hijazi, O.; Munro, S.; Zerhusen, B.; Effenberger, M. Review of life cycle assessment for biogas production in Europe. Renew. Sustain. Energy Rev. 2016, 54, 1291-1300. [CrossRef]

48. Antrop, M. Landscape change and the urbanization process in Europe. Landsc. Urban Plan. 2004, 67, 9-26. [CrossRef]

49. Cherry, C.R.; Weinert, J.X.; Xinmiao, Y. Comparative environmental impacts of electric bikes in China. Transp. Res. Part D Transp. Environ. 2009, 14, 281-290. [CrossRef]

50. Zhang, Y.; Mi, Z. Environmental benefits of bike sharing: A big data-based analysis. Appl. Energy 2018, 220, 296-301. [CrossRef]

51. Shaheen, S.A.; Zhang, H.; Martin, E.; Guzman, S. China's Hangzhou public bicycle: Understanding early adoption and behavioral response to bikesharing. Transp. Res. Rec. 2011, 2247, 33-41. [CrossRef]

52. Ricci, M. Bike sharing: A review of evidence on impacts and processes of implementation and operation. Res. Transp. Bus. Manag. 2015, 15, 28-38. [CrossRef]

53. Vasic, A.M.; Weilenmann, M. Comparison of real-world emissions from two-wheelers and passenger cars. Environ. Sci. Technol. 2006, 40, 149-154. [CrossRef] [PubMed]

54. Hawkins, T.R.; Gausen, O.M.; Strømman, A.H. Environmental impacts of hybrid and electric vehicles-A review. Int. J. Life Cycle Assess. 2012, 17, 997-1014. [CrossRef]

55. Platt, S.M.; El Haddad, I.; Pieber, S.M.; Zardini, A.A.; Suarez-Bertoa, R.; Clairotte, M.; Daellenbach, K.R.; Slowik, J.G.; Baltensperger, U.; Temime-Roussel, B.; et al. Gasoline cars produce more carbonaceous particulate matter than modern filter-equipped diesel cars. Sci. Rep. 2017, 7, 1-9.

56. Jenn, A.; Springel, K.; Gopal, A.R. Effectiveness of electric vehicle incentives in the United States. Energy Policy 2018, 119, 349-356. [CrossRef]

57. Jochem, P.; Doll, C.; Fichtner, W. External costs of electric vehicles. Transp. Res. Part D Transp. Environ. 2016, 42, 60-76. [CrossRef]

58. Sierzchula, W.; Bakker, S.; Maat, K.; Van Wee, B. The influence of financial incentives and other socio-economic factors on electric vehicle adoption. Energy Policy 2014, 68, 183-194. [CrossRef]

59. Mersky, A.C.; Sprei, F.; Samaras, C.; Qian, Z.S. Effectiveness of incentives on electric vehicle adoption in Norway. Transp. Res. Part D Transp. Environ. 2016, 46, 56-68. [CrossRef]

60. Browne, M.; Allen, J.; Nemoto, T.; Patier, D.; Visser, J. Reducing social and environmental impacts of urban freight transport: A review of some major cities. Procedia-Soc. Behav. Sci. 2012, 39, 19-33. [CrossRef]

61. Efthymiou, D.; Antoniou, C.; Tyrinopoulos, Y.; Skaltsogianni, E. Factors affecting bus users' satisfaction in times of economic crisis. Transp. Res. Part A Policy Pract. 2018, 114, 3-12. [CrossRef]

62. Grenier, A.; Page, S. The impact of electrified transport on local grid infrastructure: A comparison between electric cars and light rail. Energy Policy 2012, 49, 355-364. [CrossRef]

63. D'Alfonso, T.; Jiang, C.; Bracaglia, V. Air transport and high-speed rail competition: Environmental implications and mitigation strategies. Transp. Res. Part A Policy Pract. 2016, 92, 261-276. [CrossRef] 
64. Givoni, M. Environmental benefits from mode substitution: Comparison of the environmental impact from aircraft and high-speed train operations. Int. J. Sustain. Transp. 2007, 1, 209-230. [CrossRef]

65. Román, C.; Martín, J.C. Integration of HSR and air transport: Understanding passengers' preferences. Transp. Res. Part E Logist. Transp. Rev. 2014, 71, 129-141. [CrossRef]

66. Teske, S. Achieving the Paris Climate Agreement Goals; Springer International: Berlin/Heidelberg, Germany, 2019.

67. EU. Eurostat Passenger Transport Statistics. 2019. Available online: https://ec.europa.eu/eurostat/statisticsexplained/index.php/Passenger_transport_statistics (accessed on 13 September 2020).

68. EU. Eurostat Transport Equipment Statistics. 2019. Available online: https://ec.europa.eu/eurostat/statisticsexplained/index.php?title=Transport_equipment_statistics\&oldid=436544\#Road_transport_equipment (accessed on 13 September 2020).

69. Jonson, J.E.; Borken-Kleefeld, J.; Simpson, D.; Nyíri, A.; Posch, M.; Heyes, C. Impact of excess NOx emissions from diesel cars on air quality, public health and eutrophication in Europe. Environ. Res. Lett. 2017, 12, 094017. [CrossRef]

70. McKinsey, A.R.F. EVolution Electric Vehicles in Europe: Gearing up for a New Phase? Amsterdam Round Table: Amsterdam, The Netherland, 2014.

71. Thiel, C.; Nijs, W.; Simoes, S.; Schmidt, J.; van Zyl, A.; Schmid, E. The impact of the EU car CO2 regulation on the energy system and the role of electro-mobility to achieve transport decarbonisation. Energy Policy 2016, 96, 153-166. [CrossRef]

72. Del Pero, F.; Delogu, M.; Pierini, M. The effect of lightweighting in automotive LCA perspective: Estimation of mass-induced fuel consumption reduction for gasoline turbocharged vehicles. J. Clean. Prod. 2017, 154, 566-577. [CrossRef]

73. Garmendia, M.; Ribalaygua, C.; Ureña, J.M. High speed rail: Implication for cities. Cities 2012, 29 , S26-S31. [CrossRef]

74. Nurdden, A.; Rahmat, R.A.O.K.; Ismail, A. Effect of transportation policies on modal shift from private car to public transport in Malaysia. J. Appl. Sci. 2007, 7, 1013-1018.

75. Friman, M.; Larhult, L.; Gärling, T. An analysis of soft transport policy measures implemented in Sweden to reduce private car use. Transportation 2013, 40, 109-129. [CrossRef]

76. Ayalon, O.; Flicstein, B.; Shtibelman, A. Benefits of reducing air emissions: Replacing conventional with electric passenger vehicles. J. Environ. Prot. 2013, 4, 1035. [CrossRef]

77. Collins, G. China's Evolving Oil Demand: Slowing Overall Growth, Gasoline Replacing Diesel as Demand Driver, Refined Product Exports Rising Substantially; Working Paper; Rice University: Houston, TX, USA, 2016. 